\title{
PALM-USM v1.0: A new urban surface model integrated into the PALM large-eddy simulation model
}

\author{
Jaroslav Resler ${ }^{1,2}$, Pavel Krč ${ }^{1,2}$, Michal Belda ${ }^{1,2,4}$, Pavel Juruš ${ }^{1,2}$, Nina Benešová ${ }^{1,3}$, Jan Lopata , $^{1,3}$, Ondřej Vlček ${ }^{1,3}$, \\ Daša Damašková $^{1,3}$, Kryštof Eben ${ }^{1,2}$, Přemysl Derbek ${ }^{1}$, Björn Maronga ${ }^{5}$, and Farah Kanani-Sühring ${ }^{5}$ \\ ${ }^{1}$ Faculty of Transportation Sciences, Czech Technical University in Prague, Prague, Czech Republic \\ ${ }^{2}$ Institute of Computer Science, The Czech Academy of Sciences, Prague, Czech Republic \\ ${ }^{3}$ Air Quality Protection Division, Czech Hydrometeorological Institute, Prague, Czech Republic \\ ${ }^{4}$ Department of Atmospheric Physics, Faculty of Mathematics and Physics, Charles University, Prague, Czech Republic \\ ${ }^{5}$ Institute of Meteorology and Climatology, Leibniz Universität Hannover, Hannover, Germany
}

Correspondence to: Jaroslav Resler (reslejar@fd.cvut.cz)

Received: 9 March 2017 - Discussion started: 15 March 2017

Revised: 11 August 2017 - Accepted: 31 August 2017 - Published: 9 October 2017

\begin{abstract}
Urban areas are an important part of the climate system and many aspects of urban climate have direct effects on human health and living conditions. This implies that reliable tools for local urban climate studies supporting sustainable urban planning are needed. However, a realistic implementation of urban canopy processes still poses a serious challenge for weather and climate modelling for the current generation of numerical models. To address this demand, a new urban surface model (USM), describing the surface energy processes for urban environments, was developed and integrated as a module into the PALM large-eddy simulation model. The development of the presented first version of the USM originated from modelling the urban heat island during summer heat wave episodes and thus implements primarily processes important in such conditions. The USM contains a multi-reflection radiation model for shortwave and longwave radiation with an integrated model of absorption of radiation by resolved plant canopy (i.e. trees, shrubs). Furthermore, it consists of an energy balance solver for horizontal and vertical impervious surfaces, and thermal diffusion in ground, wall, and roof materials, and it includes a simple model for the consideration of anthropogenic heat sources. The USM was parallelized using the standard Message Passing Interface and performance testing demonstrates that the computational costs of the USM are reasonable on typical clusters for the tested configurations. The module was fully integrated into PALM and is available via its online repository under the GNU General Public License (GPL). The
\end{abstract}

USM was tested on a summer heat-wave episode for a selected Prague crossroads. The general representation of the urban boundary layer and patterns of surface temperatures of various surface types (walls, pavement) are in good agreement with in situ observations made in Prague. Additional simulations were performed in order to assess the sensitivity of the results to uncertainties in the material parameters, the domain size, and the general effect of the USM itself. The first version of the USM is limited to the processes most relevant to the study of summer heat waves and serves as a basis for ongoing development which will address additional processes of the urban environment and lead to improvements to extend the utilization of the USM to other environments and conditions.

\section{Introduction}

\subsection{Urban climate}

As more than half of the human population resides in cities, and this figure is expected to keep increasing in future (United Nations, 2014), the influence of urban surfaces on the local urban climate gains more importance. Many aspects of urban climate have direct effects on human health and living conditions, the most prominent examples being thermal comfort and air quality. 
One major phenomenon related to the urban climate is the urban heat island (UHI), i.e. the fact that an urban area may be significantly warmer than its surrounding rural areas, which mainly appears during evening and early night hours (Oke, 1982). The higher temperature is linked to the absorption and retention of energy by urban surfaces and to anthropogenic heat emissions, which can cause urban-to-rural temperature differences of several degrees Celsius. Moreover, buildings and other urban components can locally decrease the ventilation (e.g. Letzel et al., 2012), thus adding to thermal discomfort. Chemical processes, and consequently air quality, are also affected by the urban environment.

Effects of the urban heat island on living conditions have been the focus of urban planning for several decades in various cities, as it is anticipated that careful planning can alleviate some of these effects. However, developing adaptation and mitigation strategies requires state-of-the-art tools applicable for urban climatology studies. The work presented in this paper started in the larger framework of the Urban Adapt ${ }^{1}$ project, which focused on the development of such strategies for three major cities in the Czech Republic (Prague, Brno, and Pilsen). The aim was to provide as detailed a description of the street canyon conditions as possible, going to the resolution of the order of a few metres. Below we provide a brief description of the methods typically used for such a task and the motivation for developing a new urban surface model (USM).

Several possible approaches for studying urban climate have been used, ranging from observation analyses, over physical modelling, to numerical simulations (for a comprehensive review, see e.g. Mirzaei and Haghighat, 2010; Moonen et al., 2012). In this context, a number of physical processes and their complex interactions must be taken into account (e.g. Arnfield, 2003). Urban surfaces are affected by shortwave and longwave radiation, and energy is exchanged between the urban canopy and the atmosphere in various forms, including sensible and latent heat fluxes. These fluxes in turn, together with boundary layer processes and largescale synoptic conditions, affect the turbulent flow of air. The complexity is further increased by the presence of vegetation and the pronounced heterogeneity of urban surface materials.

For numerical modelling of urban climate processes, various models and frameworks have been used (Mirzaei and Haghighat, 2010; Moonen et al., 2012; Mirzaei, 2015). One possible approach is to use a regional meteorological or climate model. However, these models typically operate with horizontal resolutions of the order of hundreds of metres to tens of kilometres, and urban processes are treated using bulk parameterizations or single-/multi-layer urban canopy models (e.g. Kusaka et al., 2001; Martilli et al., 2002). Thus, these models are much better suited to assessing the influence of urban environments on the larger-scale meteorology.

\footnotetext{
${ }^{1}$ http://urbanadapt.cz/en
}

A second approach is represented by standalone parameterized models, e.g. the SOLWEIG model (Lindberg et al., 2008), RayMan (Matzarakis et al., 2010), the TUF3D model (Krayenhoff and Voogt, 2007), the TUF-IOBES model (Yaghoobian and Kleissl, 2012, based on TUF-3D), TEB (Masson, 2000), or SUEWS (Järvi et al., 2011). These models treat some physical processes (e.g. radiation, latent heat flux, water balance), while they parameterize the air flow by means of statistical and climatological models or meteorological measurements.

The most complex approach is represented by a group of computational fluid dynamics (CFD) models. The explicit simulation of the turbulent flow is computationally expensive; thus, different techniques have to be adapted to make calculations feasible, usually based on limiting the range of the resolved length scales and timescales of the turbulent flow. Most of the CFD models applied for urban climatology studies today are models based on the Reynolds-averaged Navier-Stokes (RANS) equations, e.g. ENVI-met (ENVI-met, 2009), MITRAS (Schlünzen et al., 2003), MIMO (Ehrhard et al., 2000), and MUKLIMO_3 (Sievers, 2012, 2014). In RANS models, the entire turbulence spectrum is parameterized, and thus only the mean flow is predicted. This allows for use of relatively large time steps leading to moderate computational demands, but it implies physical limitations as interactions of turbulent eddies with the urban canopy cannot be explicitly treated. In order to overcome this deficiency, large-eddy simulation (LES) models can be employed. They use a scale separation approach to resolve the bulk of the turbulence spectrum explicitly, while parameterizing only the smallest eddies in a socalled subgrid-scale model. Examples of such models are e.g. PALM (Maronga et al., 2015), which can incorporate buildings as explicit obstacles, the OpenFoam ${ }^{2}$ modelling system, which can use both LES and RANS solvers, or DALES (Heus et al., 2010).

However, many of the CFD models do not contain appropriate urban canopy energy balance models with an explicit treatment of radiative fluxes. To overcome this deficiency, stand-alone energy balance models can be coupled to CFD models, recent examples being SOLENE-microclimat (Musy et al., 2015) or TUF-IOBES, which was coupled to PALM (Yaghoobian et al., 2014). These are usually one-way coupled systems in which the stand-alone model is used for the calculation of incoming/outgoing energy fluxes to/from any surface element, which are then imported into the CFD model. This means that CFD model dynamics are not considered for the calculation of the energy fluxes, making this approach less precise than fully two-way integrated models.

Most of the CFD models are closed-source in-house solutions, complicating their scientific and technical validation. Furthermore, many of them are not designed to work on high-performance computing systems (HPC) with hundreds

\footnotetext{
${ }^{2}$ http://www.openfoam.org
} 
to thousands of processor cores, limiting their range of applications. Notable exceptions are the models PALM, OpenFoam, and DALES, which are available under a free license and can be run on HPC.

Regarding the task at hand, i.e. providing detailed information on the influence of urban surfaces and vegetation on pedestrian-level thermal comfort and air quality, LES models can be considered to be the most appropriate and futureoriented since they can predict the turbulent air flow over a very complex surface with sufficient resolution. However, according to the authors' research at the beginning of the study, there was no open-source LES model with an integrated energy balance solver for urban surfaces that would be able to account for the realistic implementation of various processes inside an urban canopy. Our attempts to integrate some of the existing energy models (e.g. TUF-3D) into PALM led to serious technical difficulties due to the different scientific approaches of the particular models, incompatible data structures, difficult parallelization, and other issues. The license compatibility was another issue. Therefore, we decided to start from scratch, extending existing LES model PALM with a new fully integrated USM module that explicitly describes energy exchanges in the urban environment. Due to the complexity of this task, the first version of PALM-USM was deliberately limited to the most important processes for modelling summer heat-wave episodes in fully urbanized areas. Further improvements and additions to this module are a current work in progress and will be realized within the next years (see also Sect. 6).

\subsection{LES model PALM}

$\mathrm{PALM}^{3}$ is designed to simulate the turbulent flow in atmospheric and oceanic boundary layers. A highlight of PALM is its outstanding scalability on massively parallel computer architectures (Maronga et al., 2015). The model solves the non-hydrostatic incompressible Navier-Stokes equations in Boussinesq approximation. Subgrid-scale processes that cannot be resolved implicitly based on the numerical grid resolution are parameterized according to the 1.5-order Deardorff closure scheme (Deardorff, 1980) with the modification of Moeng and Wyngaard (1988) and Saiki et al. (2000), assuming that the energy transport by subgrid-scale eddies is proportional to the local gradients of the mean quantities.

Prognostic equations are solved numerically, primarily using an upwind biased fifth-order differencing scheme (Wicker and Skamarock, 2002) and a third-order RungeKutta time-stepping scheme following Williamson (1980). Discretization in space is achieved using finite differences on a staggered Cartesian Arakawa-C grid (Arakawa and Lamb, 1977).

PALM includes several features, such as cloud microphysics, a plant canopy model, and an embedded Lagrangian

\footnotetext{
${ }^{3}$ https://palm.muk.uni-hannover.de
}

particle model. In connection with the urban application, four other relevant schemes have already been implemented: a Cartesian topography scheme, representation of radiative exchange at the surface, large-scale forcing, and land-surface interactions with the atmosphere. The Cartesian topography scheme covers solid, impermeable, fixed flow obstacles (e.g. buildings) as well as terrain elevations (mountains, hills), with a constant-flux layer assumed between each surface element and the first grid level adjacent to the respective surface in order to account for friction effects. The representation of radiative exchange at the surface contains options to use either a simple clear-sky radiation parameterization or employ the Rapid Radiation Transfer Model for Global Models (RRTMG, e.g. Clough et al., 2005), which is coupled to PALM and is applied as a single-column model for each vertical column in the PALM domain. The large-scale forcing option enables forcing with data e.g. from mesoscale models via additional tendency terms, including an option for nudging of the mean profiles. Finally, the implementation of landsurface interactions with the atmosphere is based on a simplified version of the Tiled European Centre for MediumRange Weather Forecasts Scheme for Surface Exchanges over Land (TESSEL/HTESSEL, Balsamo et al., 2009) and its derivative implementation on the DALES model (Heus et al., 2010). PALM's land-surface submodel (Maronga and Bosveld, 2017), hereafter referred to as PALM-LSM, further extends the surface parameterizations for impervious surfaces on the ground (pavements, roads) by replacing upper soil layers with a pavement layer attributed with a specific heat capacity and heat conductivity.

However, none of the included schemes are suited for treating complex effects of the urban environment driven by the diverse physical properties of different urban surfaces (both horizontal and vertical), heat transfer within building walls, and heat fluxes between the urban surfaces and the atmosphere. Also, the description of shortwave and longwave radiation budgets including shading and multi-reflection between surfaces, as well as the absorption of radiation by plant canopies, have not been treated by PALM so far. Therefore, we developed the USM for PALM that is able to treat these processes using approaches described in the following section.

\section{Urban surface model}

In this section, the first version of the new USM for PALM is described. The USM consists of a solver for the energy balance of all horizontal and vertical urban surface elements, including building walls and roofs, as well as pavements. The energy balance solver predicts the skin layer temperature, and it simultaneously calculates the near-surface turbulent flux of sensible heat and the subsurface conductive heat flux. The latter is calculated by means of a multi-layer model predicting heat diffusion through solid material. Moreover, 
a multi-reflection radiative transfer model (RTM) for the urban canopy layer was developed, and coupled to the plant canopy model in order to calculate realistic surface radiative fluxes as input for the energy balance solver.

This first version of the USM was designed with the focus on modelling summer heat-wave episodes in built-up urban areas. The newly implemented methods hence concentrated on the most relevant processes for such conditions. Limitations of the current version are e.g. no treatment of reflective surfaces and windows; only a basic building energy model; simplification of some radiation-related processes (see Sect. 2.2.1 for details); a missing plant-canopy evapotranspiration model; and surfaces impervious to water. Possible impacts of these limitations are discussed in Sect. 4. Improvements of the USM and related PALM components are subject to ongoing development within the PALM community.

\subsection{Energy balance solver}

The surface energy balance correlates radiative energy fluxes with sensible and latent heat fluxes between the surface skin layer and the atmosphere, as well as with the storage heat fluxes into soil and walls. In this first PALM-USM version, latent heat fluxes were omitted, since the purpose of this version was to simulate heat-wave episodes in fully urbanized areas. This limitation is discussed in Sect. 4.1. The energy budget is expressed in the form

$C_{0} \frac{\mathrm{d} T_{0}}{\mathrm{~d} t}=R_{\mathrm{n}}-H-G$,

where $C_{0}$ and $T_{0}$ are the heat capacity and temperature of the surface skin layer, respectively, $t$ is the time, $R_{\mathrm{n}}$ is the net radiation, $H$ is the turbulent sensible heat flux near the surface, and $G$ is the heat flux from the surface skin layer into the ground or material (i.e. pavement, walls, roofs). The list of all used symbols, their descriptions, and units can be found in the Supplement in Table S1.

The calculation of the heat transfer $H$ between the surface skin layer and the air is based on the equation

$H=h\left(\theta_{1}-\theta_{0}\right)$,

where $\theta_{0}$ is the potential temperature at the surface and $\theta_{1}$ is the potential temperature of the air layer adjacent to the surface; and $h$ is the so-called heat flux coefficient, which is parameterized for vertical surfaces according to Krayenhoff and Voogt (2007), while for horizontal surfaces the parameterization of $h$ follows the default PALM-LSM formulation based on Monin-Obukhov similarity theory (Obukhov, 1971). The latter involves the calculation of a local friction velocity, for which stability effects are considered for horizontal surfaces, while stability for vertical surfaces is treated as neutral (i.e. law-of-the-wall scaling is used). The friction velocity is used to calculate both the surface momentum flux for each individual surface element and the coefficient $h$ for

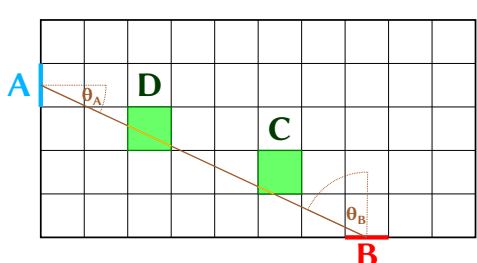

(a)

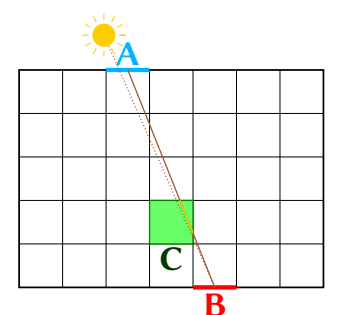

(b)
Figure 1. (a) View factor calculation (2-D simplification); (b) direct solar irradiation.

horizontal surface elements. The application of MOST for finite-sized surfaces is debatable as the theory is based on the assumption of horizontal homogeneity of the surface and flow, which is violated in urban areas. However, for lack of alternatives, it is the common modelling approach used in all state-of-the-art surface parameterization schemes (e.g. TUF-3D, Krayenhoff and Voogt, 2007; SUEWS, Järvi et al., 2011). The use of MOST in PALM as a boundary condition for buildings has been validated for neutral stratification by Letzel et al. (2008) and Kanda et al. (2013). Moreover, Park and Baik (2013) validated their LES results for non-neutral stratification against wind-tunnel data.

The heat transfer between surface skin layer and subsurface layers follows the general formulation for the heat flux $G$ :

$G=\Lambda\left(T_{0}-T_{\text {matter, } 1}\right)$,

where $T_{0}$ is the temperature of the surface skin layer, $T_{\text {matter, } 1}$ is the temperature of the outermost layer of the material, and $\Lambda$ is an empirical heat conductivity between the skin layer and the first grid level in the material.

The heat transfer within the material layers is calculated via the Fourier law of diffusion. This approach has been generalized for different material types of the pavements, walls, and roofs, each structured into four layers; each layer of each material is described by its own properties (thickness, volumetric thermal capacity, and thermal conductivity). The diffusion equation is solved numerically describing the heat transfer from the surface into the inner layers. Boundary conditions of the deepest layer are prescribed in the configuration for particular types of surfaces and are kept constant throughout the simulation. The flux $G$, calculated in the surface energy balance model, serves as a boundary condition for the outermost material layer.

All non-linear terms in Eq. (1) are linearized to avoid the need for an iteration method to solve for the skin temperature (see Maronga and Bosveld, 2017). Equation (1) is then solved by PALM's default Runge-Kutta scheme. The nearsurface heat fluxes are evaluated based on the new prognostic skin layer temperature. 


\subsection{Radiative transfer model}

\subsubsection{General concept}

The USM receives radiation from the standard PALM solar radiation model at the top boundary of the urban canopy layer. Depending on the chosen radiation module in PALM, the separate direct and diffuse components of the downward shortwave radiation flux may or may not be available. In the latter case, a simple statistical splitting is applied based on Boland et al. (2008). The USM then adds a description of radiation processes in the urban canopy layer where multiple reflections are considered.

Radiation processes are modelled separately for shortwave (SW) and longwave (LW) radiation. Direct and diffuse SW solar radiation along with the relative position of the Sun, as well as the LW radiation from the atmosphere, is provided by PALM's solar radiation model. Thermal emission from the ground, walls, and roofs is added as a source of longwave radiation. For each time step, radiation is propagated through the 3-D geometry of the urban canopy layer for a finite number of reflections, after which all of the radiation is considered fully absorbed by the surfaces. All reflections are treated as diffuse (Lambertian), and in each reflection, a portion of radiation is absorbed by the respective surface according to its properties (albedo and emissivity). The urban layer may contain an arbitrarily located plant canopy (trees and shrubs) described by a 3-D structure of leaf area density (LAD), which is treated as semi-opaque for the modelled SW radiation and transforms the absorbed radiation to heat (see Sect. 2.2.4).

Some radiation-related processes have been omitted in this first version, including absorption, emission, and scattering by air within the urban canopy layer, interaction of LW radiation with plant canopy, and thermal capacity of plant leaves (plant canopy is assumed to have the temperature of the surrounding air). The effects of these simplifications are discussed in Sect. 4.

\subsubsection{Calculation of view factors and canopy sink factors}

For the calculation of irradiation of each face ${ }^{4}$ from diffuse solar radiation, thermal radiation, and reflected radiation, mutual visibility between faces of both real surfaces and virtual surfaces (top and lateral domain boundaries) has to be known. It is calculated using a ray tracing algorithm. Since this process is computationally expensive and hard to parallelize (as rays can travel through the entire domain which is distributed on different processors), both the view factors (SVF) and the plant-canopy sink factors (CSF) are precomputed during the model initialization. These factors can be

\footnotetext{
${ }^{4} \mathrm{~A}$ face is a unit of surface according to discretization by grid; it is a boundary between a grid box with terrain/building and an adjacent air-filled grid box.
}

saved to file and used for other simulations with the same surface geometry, or for the calculation of the mean radiant temperature (MRT) in the postprocessing.

For any two faces $A$ and $B$ with mutual visibility, the view factor $F_{A \rightarrow B}$ represents the fraction between that part of the radiant flux from face $A$ that strikes face $B$ and the total radiant flux leaving face $A$. For infinitesimally small areas of $A$ and $B$, a differential view factor $F_{A \rightarrow B}^{\mathrm{d}}$ can be written as

$F_{A \rightarrow B}^{\mathrm{d}}=\frac{\mathrm{d} F_{A \rightarrow B}}{\mathrm{~d} \mathcal{A}(B)}=\frac{\cos \theta_{A} \cos \theta_{B}}{\pi s^{2}}$,

where $\mathcal{A}(B)$ is the surface area of face $B, \theta_{A}$ and $\theta_{B}$ are the angles between the respective face normals and the connecting ray, and $s$ is the separation distance (ray length) (Howell et al., 2010); see Fig. 1a. Under the assumption that $s$ is much larger than the grid resolution, differential view factors are precomputed for all mutually visible face centres and used in place of view factors divided by target area. At the end, the differential view factors are normalized such that the sum of all normalized differential view factors with the same target face $(B)$ multiplied by source area equals 1 :

$\widehat{F}_{A \rightarrow B}^{\mathrm{d}}=\frac{F_{A \rightarrow B}^{\mathrm{d}}}{\sum_{A^{\prime}} F_{A^{\prime} \rightarrow B}^{\mathrm{d}} \mathcal{A}\left(A^{\prime}\right)}$.

If the view factors were known exactly, the sum $\sum_{A^{\prime}} \frac{F_{A^{\prime} \rightarrow B} \mathcal{A}\left(A^{\prime}\right)}{\mathcal{A}(B)}$ would equal 1 (from the reciprocity rule $\left.\mathcal{A}(A) F_{A \rightarrow B}=\mathcal{A}(B) F_{B \rightarrow A}\right)$. Therefore, the normalization guarantees that, in total, no radiation is lost or created by simplification due to discretization. Since the part of face $B$ 's irradiance that comes from face $A$ is computed as

$J_{e, A \rightarrow B}=E_{e, A} \mathcal{A}(A) \widehat{F}_{A \rightarrow B}^{\mathrm{d}}$,

where $E_{e, A}$ is the radiosity of face $A$, we specifically precompute and store the value of

$\mathrm{SVF}_{A \rightarrow B}=\mathcal{A}(A) \widehat{F}_{A \rightarrow B}^{\mathrm{d}}$

which we call the irradiance factor. In case the ray tracing algorithm encounters an obstacle (i.e. wall or roof), the viewfactor entry is not stored, indicating the absence of mutual visibility between the two respective faces.

The equations above describe radiative fluxes before accounting for plant canopy. For every ray that crosses a grid box containing plant canopy (i.e. a partially opaque box), a dimensionless ray canopy sink factor (RCSF) represents the radiative flux absorbed within the respective grid box normalized by the total radiative flux carried by the ray at its origin. For a ray $A \rightarrow B$ and a grid box $C$, the RCSF is calculated as

$\operatorname{RCSF}_{C, A \rightarrow B}=\left(1-\sum_{D} \operatorname{RCSF}_{D, A \rightarrow B}\right)\left(1-e^{-\alpha a_{C} s_{C}}\right)$,

where $a_{C}$ is the leaf area density of grid box $C, s_{C}$ is the length of the ray's intersection with box $C$, and $\alpha$ is the 
extinction coefficient. The sum in the first term represents cumulative absorption by all plant-canopy-containing grid boxes $D$ that have already been encountered on the ray's path before reaching grid box $C$ (Fig. 1a).

After the entire ray is traced, the total transmittance $T$ of the ray $A \rightarrow B$ passing through plant canopy grid boxes $C$

$T_{A \rightarrow B}=1-\sum_{C} \operatorname{RCSF}_{C, A \rightarrow B}$

is stored along with $\mathrm{SVF}_{A \rightarrow B}$. Later in the modelling, when the radiant flux transmitted through $\mathrm{SVF}_{A \rightarrow B}$ is calculated, it is multiplied by $T_{A \rightarrow B}$ to account for the absorbed flux.

The actual radiant flux $\Phi_{e}$ received by the grid box $C$ from the ray $A \rightarrow B$ is equal to

$\Phi_{e, C, A \rightarrow B}=E_{e, A} \cdot \mathrm{SVF}_{A \rightarrow B} \cdot \mathcal{A}(B) \cdot \mathrm{RCSF}_{C, A \rightarrow B}$.

The radiosity $E_{e, A}$ of the source face is the only timedependent variable in this equation. Therefore, the rest of this product can be precomputed during initialization, and summed up per source face in the form of a canopy sink factor (CSF):

$\mathrm{CSF}_{C, A}=\sum_{B} \operatorname{SVF}_{A \rightarrow B} \cdot \mathcal{A}(B) \cdot \mathrm{RCSF}_{C, A \rightarrow B}$.

CSF represents the ratio between the radiant flux absorbed within plant canopy box $C$ originating from face $A$ and the radiosity of face $A$.

\subsubsection{Calculation of per-face irradiation}

At each time step, the total incoming and outgoing radiative fluxes of each face are computed iteratively, starting from the first pass of radiation from sources to immediate targets, followed by consecutive reflections.

In the first pass, the virtual surfaces (sky and domain boundaries) are used as sources of radiation by representing components of diffuse shortwave solar radiation and longwave radiation from the sky. At this point, the real surfaces (wall facades, roofs, ground) are set to emit longwave radiation according to their surface temperature and emissivity. The precomputed view factors are then used to cast the shortwave and longwave radiation from source to target faces.

Solar visibility has to be calculated for the quantification of the direct part of shortwave solar radiation. The solar angle is discretized for this purpose so that the solar ray always originates from the centre of the virtual face at the top of the urban layer or at lateral domain boundaries (see the real location of the Sun vs. the discretized location (centre of face $A$ ) in Fig. 1b). We have decided not to do the computationally expensive ray tracing after the precomputation phase is over; moreover, the total transmittance stored alongside the precomputed view factor (see Eq. 9) is readily available. If there is no such view factor entry, it means that the discretized ray path is blocked by a wall or roof and the target face receives no direct solar irradiation. For the purpose of calculating the actual amount of direct solar irradiation, an exact solar angle is used, not the discretized one.

After the aforementioned first pass of radiation from source to target surfaces has been computed, reflection is applied iteratively. At each iteration, a fraction of each surface's irradiation from the previous iteration is reflected and the remainder is considered absorbed. The reflected fraction is determined by the surface's albedo for shortwave radiation and by the surface's emissivity $\varepsilon$ for longwave radiation, where the longwave reflectivity results from $(1-\varepsilon)$ according to Kirchhoff's law. The reflected part is then again distributed onto visible faces using the precomputed view factors. After the last iteration, all residual irradiation is considered absorbed. The number of iterations is configurable, and the amount of residual absorbed radiation can be displayed in the model output. In our experience, three to five iterations lead to negligible residue.

\subsubsection{Absorption of radiation in the plant canopy}

The fraction of SW radiative flux absorbed by the plant canopy is calculated for the first pass as well as for all the successive reflection steps (these are described in Sect. 2.2.3).

For diffuse and reflected shortwave radiation, the amount of radiative flux absorbed by each grid box with plant canopy is determined using the precomputed CSF and radiosity of the source face (i.e. reflected radiosity for a real surface or diffuse solar irradiance for a virtual surface; see Eq. 10).

For the direct solar irradiance, the nearest precomputed ray path from the urban-layer bounding box (represented by virtual face $A$ in Fig. 1b) to the respective plant canopy grid box $C$ is selected similarly to the direct surface irradiation described in Sect. 2.2.3. In case the grid box $C$ is fully shaded, no ray path is available. Otherwise, the transmittance of the path is known. The absorbed direct solar flux for the grid box $C$ is equal to

$\Phi_{e, C}=E_{e, \operatorname{dir}} \cdot T_{A \rightarrow C} \cdot \frac{\iint_{b}\left(1-e^{-\alpha a_{C} s_{b}}\right) \mathrm{d} b}{\mathcal{A}_{C}^{\prime}}$,

where $E_{e \text {,dir }}$ is the direct solar irradiance and $\mathcal{A}_{C}^{\prime}$ is the crosssectional area of $C$ viewed from the direction of the solar radiation. The fraction in Eq. (12) represents the absorbed proportion of radiative flux, averaged over each ray $b$ that intersects the grid box $C$, and is parallel to the direction of the solar radiation; $s_{b}$ is the length of the intersection. Since all grid boxes have the same dimensions, this fraction is precomputed based on the solar direction vector at the beginning of each time step using discrete approximation.

Once the total absorbed radiative flux is known, it is stored as plant canopy heat rate for the respective grid box. Since the plant canopy is considered to have zero thermal capacity, all of the heating power is applied immediately to the grid box's air volume. 


\subsection{Anthropogenic heat}

The prescribed anthropogenic heat is assigned to the appropriate layer of the air, where it increases the potentialtemperature tendencies at each time step. This process takes place after the surface energy balance is solved. The heat is calculated from daily total heat released into any particular grid box, and from the daily profile of the release specified for every layer to which anthropogenic heat is released.

\subsection{USM module integration into PALM}

The USM was fully integrated into PALM, following its modular concept, as an optional module, which directly utilizes the model values of wind flow, radiation, temperature, energy fluxes, and other required values. The USM returns the predicted surface heat fluxes back to the PALM core, where they are used in the corresponding prognostic equations. It also adjusts the prognostic tendencies of air according to released anthropogenic heat.

Descriptions of real and virtual surfaces and their properties are stored in 1-D arrays indexed to the 3-D model domain. The crucial challenge of this part of the design is to ensure an efficient parallelization of the code, including an efficient handling and access of data stored in the memory during the simulation. The values are stored locally in particular processes of the Message Passing Interface $\left(\mathrm{MPI}^{5}\right)$, corresponding to the parallelization of the PALM core. Necessary access to values stored in other processes is enabled by means of MPI routines, including interfaces for one-sided MPI communication.

The configuration of the USM module is compatible with other PALM modules. Variables for instantaneous and timeaveraged outputs of the USM are integrated into PALM's standard 3-D NetCDF output files, and they are configured in the same way as the rest of the model output variables. The configuration options as well as the structure of input and output files are described in the Supplement to this article. The Supplement also contains the list and description of needed surface and material parameters of urban surfaces, plant-canopy data, and anthropogenic-heat data. The model PALM with its USM module is hereafter referred to as PALM-USM, which is freely available under the GNU General Public License (see the Code availability section).

\section{Evaluation and sensitivity tests of the USM}

In order to evaluate how well the USM represents urban surfaces' temperatures (of e.g. walls, roofs, and streets), a summer heat-wave observation campaign in an urban quarter of Prague, Czech Republic, was carried out (see Sect. 3.1). By means of PALM-USM, urban-quarter characteristics and the campaign's meteorological conditions were simulated (see

\footnotetext{
${ }^{5} \mathrm{http}: / / \mathrm{mpi}$-forum.org
}

Sect. 3.2) and model results evaluated against the observations (see Sect. 3.3).

\subsection{Observation campaign}

The campaign was carried out at the crossroads of Dělnická street and Komunardů street in Prague, Czech Repub$\operatorname{lic}\left(50.10324^{\circ} \mathrm{N}, 14.44997^{\circ} \mathrm{E}\right.$; terrain elevation $180 \mathrm{~m}$ a.s.l.). This location was selected in coordination with the Prague Institute of Planning and Development as a case study area for urban heat island adaptation and mitigation strategies. This particular area represents a typical residential area in a topographically flat part of the city of Prague with a combination of old and new buildings and a variety of other urban components (such as yards or parking spaces). The streets are oriented in the north-south (Komunardü) and west-east (Dělnická) directions, roughly 20 and $16 \mathrm{~m}$ wide, respectively. The building heights alongside the streets range approximately from 10 to $25 \mathrm{~m}$. The area does not contain much green vegetation and the majority of the trees is located in the yards. The neighbourhood in the extent of approximately $1 \mathrm{~km}^{2}$ has similar characteristics to the study area (see the aerial photo in Fig. 2).

Measurements were conducted from 2 July 2015, 14:00 UTC to 3 July 2015, 17:00 UTC. The timing of the measurement campaign was chosen to cover a typical summer heat-wave episode.

\subsubsection{Measurements}

Wall and ground surface temperatures were measured by an infrared camera - FLIR SC660 (FLIR, 2008). The thermal sensor of the camera has a field of view of 24 by $18^{\circ}$ and a spatial resolution (given as an instantaneous field of view) of $0.65 \mathrm{mrad}$. The spectral range of the camera is 7.5 to $13 \mu \mathrm{m}$, and the declared thermal sensitivity at $30^{\circ} \mathrm{C}$ is $45 \mathrm{mK}$. The measurement accuracy for an object with a temperature between +5 and $+120^{\circ} \mathrm{C}$, and given an ambient air temperature between +9 and $+35^{\circ} \mathrm{C}$, is $\pm 1^{\circ} \mathrm{C}$, or $\pm 1 \%$ of the reading. The camera offers a built-in emissivity-correction option, which was not used for this study. Apart from the infrared pictures, the camera allows us to take pictures in the visible spectrum simultaneously.

Observation locations are shown in Fig. 3, eight of them (Nos. 1-7 and 9) representing temperature measurements of the walls on the opposite side of the street, and one of them (No. 8) representing the ground-temperature measurement on the road. The camera was always placed on a tripod at about $1.6 \mathrm{~m}$ above ground, with its orientation approximately perpendicular to the opposite walls, at a distance of 14-18 m depending on the street width. For scans of the ground, the picture's centre was viewed under an angle of about $15^{\circ}$ (the closest point was approx. $2 \mathrm{~m}$ away and the most distant point $30 \mathrm{~m}$, resulting in view angles of 38 and $3^{\circ}$, respectively). Pictures in both the infrared and visible spectra were taken 


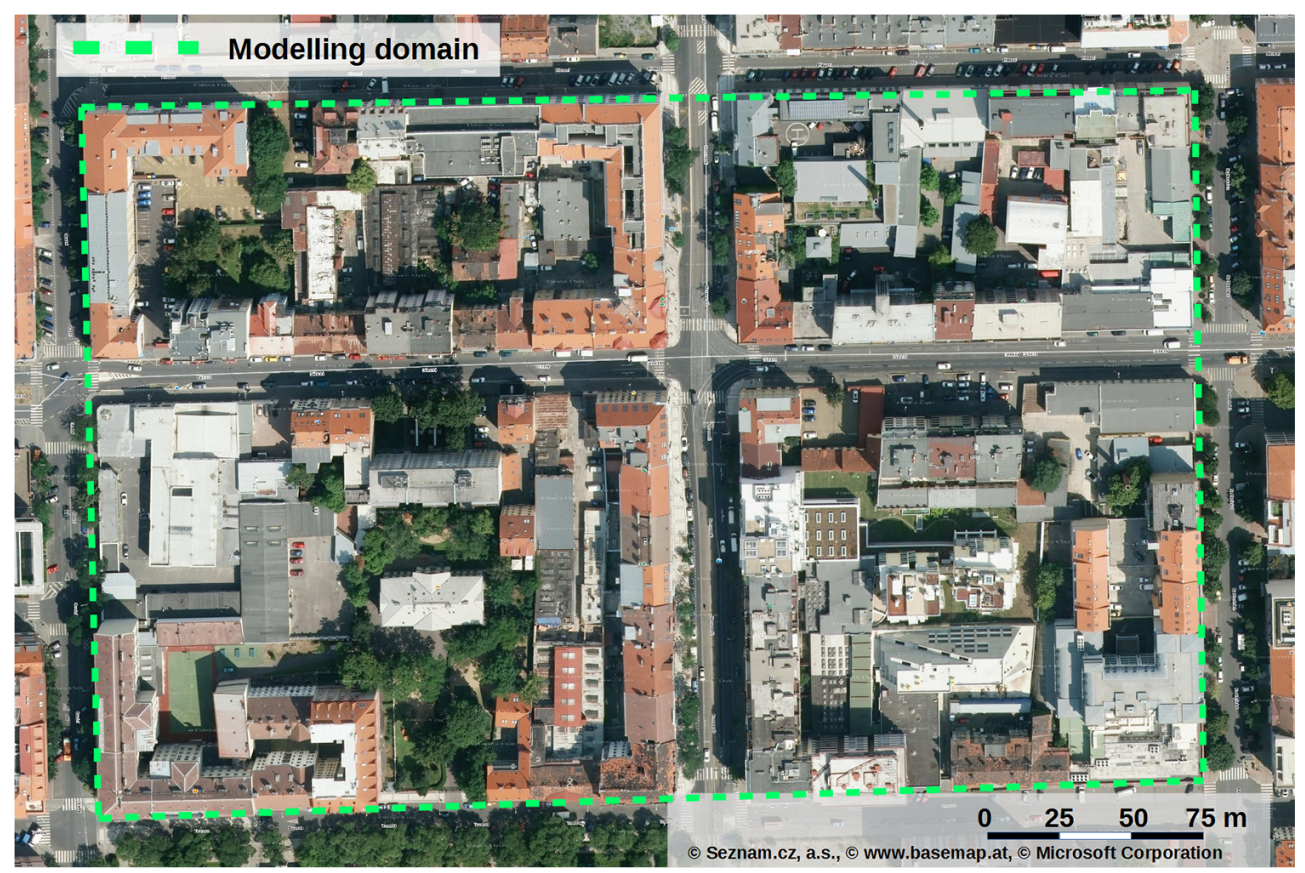

Figure 2. Aerial photo of the studied area.

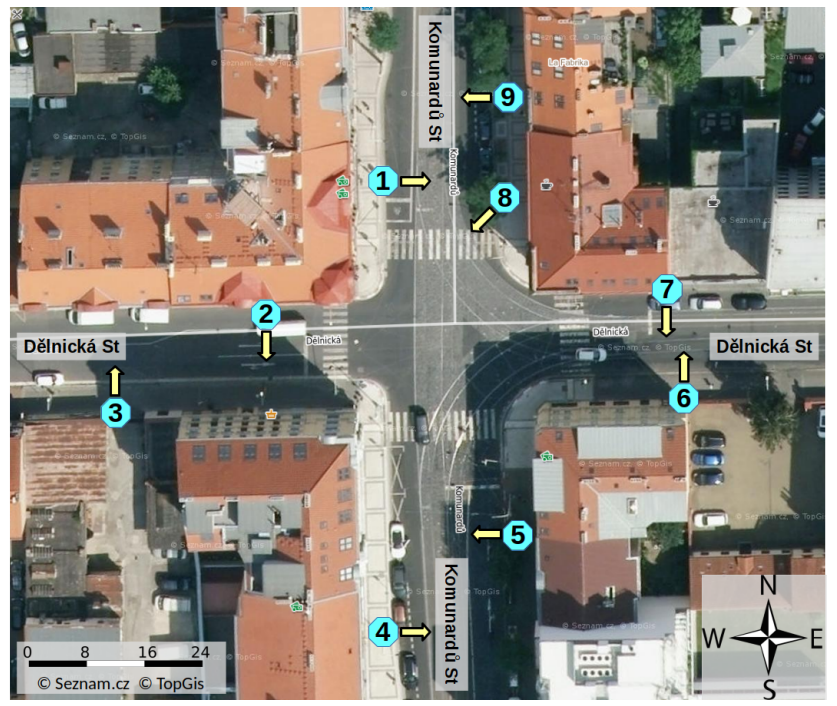

Figure 3. Observation locations. Arrows depict the orientation of the camera view. Url of the map: https://mapy.cz/s/12Qd8.

simultaneously, starting at observation location 1 every full hour and continuing through observation locations 2,3 , etc. This provided a series of 28 temperature snapshots per location with an approximately $1 \mathrm{~h}$ time step. The exact recording time of each picture was used for further processing and evaluation of the model.

The pictures were further postprocessed. First, the infrared pictures were converted into a common temperature scale +10 to $+60^{\circ} \mathrm{C}$. Second, the pictures were transformed to overlap each other in order to correct for slight changes in camera position between the measurements, as the camera was carried from one location to another. Third, several evaluation points were selected for each view to cover various surface types in order to evaluate the model performance under different surface parameter settings (different surface materials and colours) and under different situations (fully irradiated or shaded areas). That is, selected surface materials comprised old and new plastered brick house walls as well as modern insulated facades for vertical surfaces, and pavement or asphalt for the ground observation location. With regard to colours, the evaluation points were placed on both dark and light surfaces, with special interest in places where light and dark materials are located side-by-side, thus allowing one to inspect different albedo settings under roughly the same irradiance conditions. Some points were placed on wall areas, which are temporarily (in the diurnal cycle) shaded by trees or buildings, in order to test how the shading works in the model.

Apart from infrared camera scanning, the air temperature was measured once an hour at observation location 1 at the edge of the pavement, about $2 \mathrm{~m}$ apart from the wall and $2 \mathrm{~m}$ above ground, and not in direct sunlight. A digital thermometer with an external NTC-type thermistor measuring probe (resolution of $0.1 \mathrm{~K}$ and declared accuracy of $1 \mathrm{~K}$ ) was used. This on-site measurement did not meet requirements for the standard meteorological measurement; therefore, we refer to it as the indicative measurement later in the text.

Further meteorological data were acquired from the official weather monitoring network, including stations 


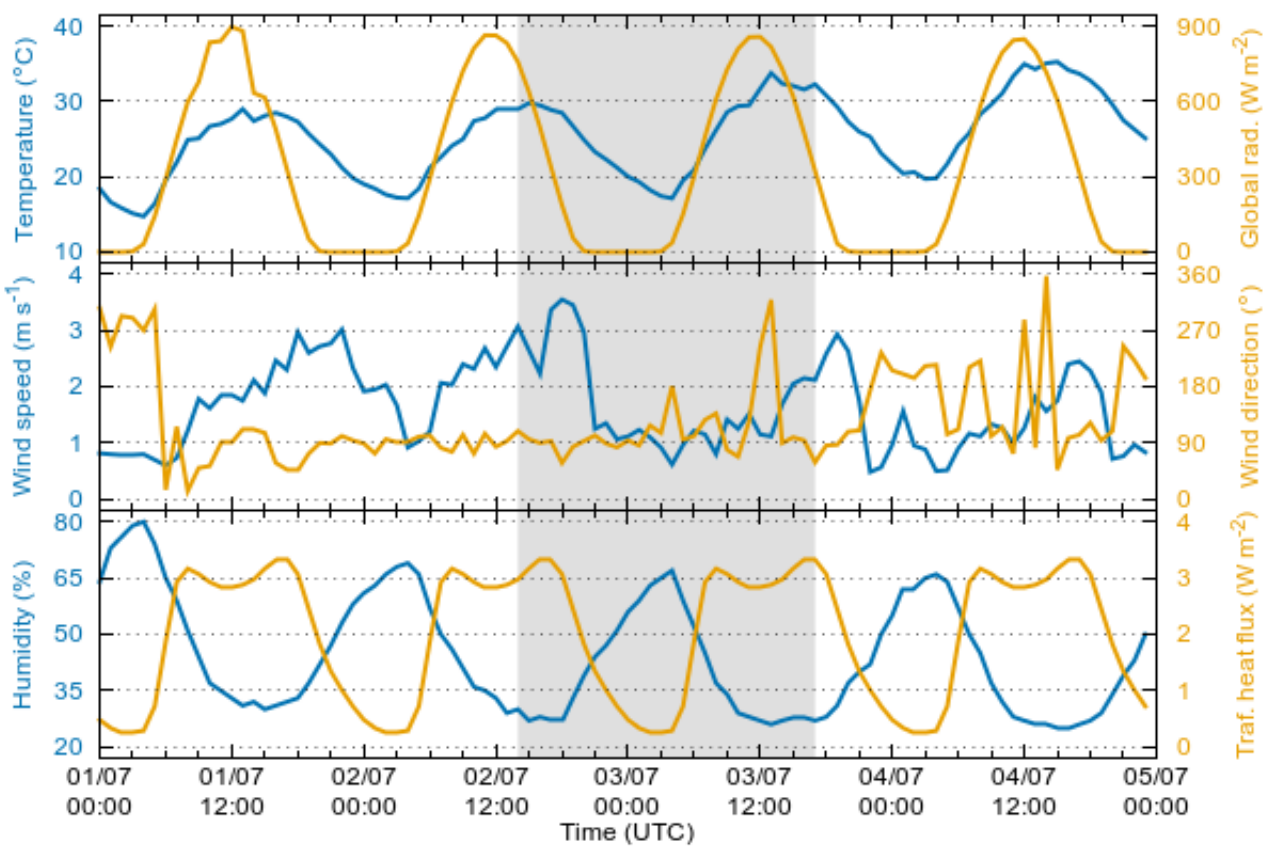

Figure 4. Meteorological conditions from station Prague, Karlov, and spatially averaged traffic heat flux from 1 to 4 July. The shaded area marks the time of the observation campaign.

Prague, Klementinum; Prague, Karlov; Prague, Kbely; and Prague, Libuš. Station Prague, Klementinum $\left(50.08636^{\circ} \mathrm{N}\right.$, $14.41634^{\circ} \mathrm{E}$; terrain elevation $190 \mathrm{~m}$ a.s.l., $3 \mathrm{~km}$ away from the crossroads of interest) was used as supplementation to the on-site indicative measurement. The temperature at this station is measured on the north-facing wall, $10 \mathrm{~m}$ above the courtyard of the historical building complex, and it can be used as another reference for the air temperature inside the urban canopy. Station Prague, Karlov $\left(50.06916^{\circ} \mathrm{N}\right.$, $14.42778^{\circ}$ E, 232 ma.s.1.; $4.3 \mathrm{~km}$ away), can be considered representative for the city core of Prague as it is located in the centre of the city. Station Prague, Kbely $\left(50.12333^{\circ} \mathrm{N}\right.$, $14.53806^{\circ} \mathrm{E}, 285 \mathrm{~m}$ a.s.l.; $6.7 \mathrm{~km}$ away), is located at the border of the city and serves as a reference for regional background suburban meteorological conditions. Station Prague, Libuš $\left(50.00778^{\circ} \mathrm{N}, 14.44694^{\circ} \mathrm{E}, 302 \mathrm{~m}\right.$ a.s.l.; $10 \mathrm{~km}$ away), is located in the city suburb and it is the only station with sounding measurements in the area. Radiosondes are released three times a day (00:00, 06:00, 12:00 UTC).

\subsubsection{Weather conditions}

The weather during the campaign was influenced by a highpressure system centred above the Baltic Sea. The meteorological conditions at Prague, Karlov station, are shown in Fig. 4. Winds above rooftop were weak, mostly below $2.5 \mathrm{~m} \mathrm{~s}^{-1}$, and often as low as $1 \mathrm{~m} \mathrm{~s}^{-1}$ from easterly directions. The maximum measured wind speeds of $3-4 \mathrm{~m} \mathrm{~s}^{-1}$ were observed in the afternoons at the beginning and at the end of the campaign. According to the atmospheric sounding, a low-level jet from the south and south-east was observed during the night, with a maximum wind speed of $10 \mathrm{~m} \mathrm{~s}^{-1}$ at $640 \mathrm{ma.s.1}$. ( $950 \mathrm{hPa}$ ) (not shown). The temperature exceeded $30^{\circ} \mathrm{C}$ in the afternoons and dropped to $20^{\circ} \mathrm{C}$ at night. The sky was mostly clear with some clouds during the daytime on 1 July and high-altitude cirrus forming in the morning and afternoon on 3 July. The highest values of relative humidity occurred at night (65\%), dropping to $30 \%$ during the day. The time of the sunset was 19:15 UTC on 2 July 2015 , and the time of sunrise and solar noon on 3 July was 02:58 and 11:06 UTC.

\subsection{Model set-up and input data for USM}

To assess the validity of the model formulation and its performance in real conditions, the model was set up to simulate the measured summer episode described in Sect. 3.1. The total simulation time span was $48 \mathrm{~h}$, starting on 2 July 2015 , 00:00 UTC.

\subsubsection{Model domain}

The horizontal size of the model domain was $376 \mathrm{~m} \times 226 \mathrm{~m}$ (see Fig. 2) at a resolution of $2.08 \mathrm{~m} \times 2.08 \mathrm{~m}$. The vertical grid spacing was $2.08 \mathrm{~m}$ within the first $50 \mathrm{~m}$, and above this level, a vertical stretching factor of 1.08 between two adjacent levels was used with a maximum grid spacing of $20 \mathrm{~m}$. The resulting total domain height was about $3.5 \mathrm{~km}$. The relatively small horizontal model domain was chosen due to available data of surface parameters and to keep com- 
Sounding Prague, Libuš 2015-07-02T00:00

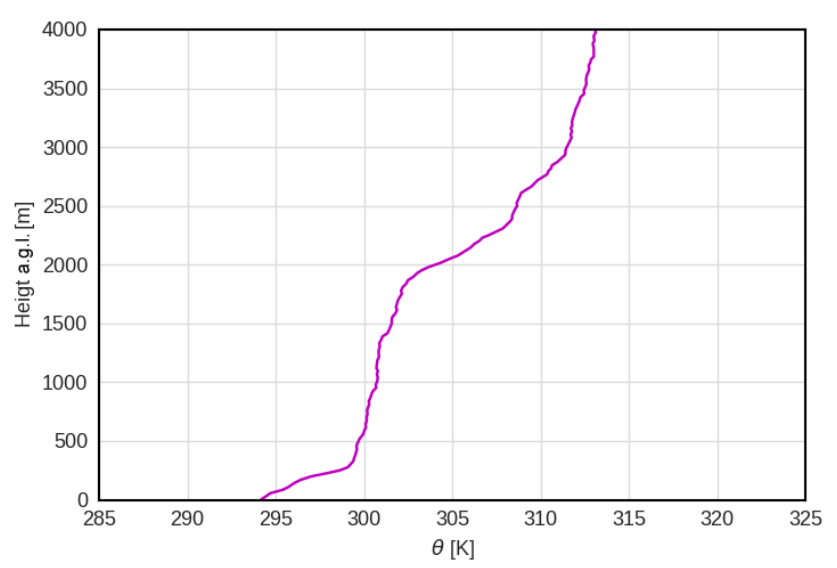

Figure 5. Initial vertical profile of potential temperature $(\theta)$ as used for initialization of PALM.

putational demands feasible. This poses some limitation to the turbulence development during the daytime, where the largest eddies usually scale with the height of the boundary layer. These eddies could not be captured well with this configuration. The effects of the limited horizontal size of the domain on model results will be discussed in Sect. 4 .

\subsubsection{Boundary and initial conditions}

Lateral domain boundaries were cyclic, which can be envisioned as an infinite repetition of the simulated urban quarter. This is a reasonable approximation, since the surrounding area has similar characteristics to the model domain; thus, the character of the flow can be considered similar. The bottom boundary was driven by the heat fluxes as calculated by the energy balance solver (see Sect. 2.1). At the top of the domain, Neumann boundary conditions were applied for potential temperature and relative humidity, while a Dirichlet boundary was set for the horizontal wind. A weak Rayleigh damping with a factor of 0.001 was applied to levels above $3000 \mathrm{~m}$. The indoor temperature was fixed at $22^{\circ} \mathrm{C}$ during the entire simulation.

The initial vertical profile of potential temperature of air was derived from the sounding measurement in the outskirts of Prague, Libuš station, from 2 July 2015, 00:00 UTC (see Fig. 5). At midnight, a stable layer had developed near the surface, extending to a height of about $300 \mathrm{~m}$. Above, a residual layer with slightly stable stratification ranged up to the inversion at around $1900 \mathrm{~m}$. The capping inversion had a strength of about $5 \mathrm{~K}$, with the stable free atmosphere aloft. The temperature of walls, grounds, and roofs was initialized from a $24 \mathrm{~h}$ spin-up simulation.

\subsubsection{Large-scale forcing}

To account for the processes occurring on larger scales than the modelling domain but still affecting the processes inside the domain, the large-scale forcing option of PALM was used. The effect of large-scale conditions is included via geostrophic wind and large-scale advection tendencies for temperature and humidity. The forcing quantities can depend on both height and time while being horizontally homogeneous. Nudging of PALM quantities towards the largescale conditions was enabled for the free atmosphere layers with a relaxation time of $7 \mathrm{~h}$. Inside the boundary layer nudging was disabled. Large-scale forcing and nudging data were generated based on a run with the WRF meso-scale numerical weather prediction model (version 3.8.1, Skamarock et al., 2008). The WRF simulation domain covered a large part of Europe $\left(-1.7-34.7^{\circ}\right.$ longitude, 41.4$56.7^{\circ}$ latitude; $9 \mathrm{~km}$ horizontal resolution, 49 vertical levels). Standard physics parameterizations were used, including the RRTMG radiation scheme, the Yonsei University PBL scheme (Hong et al., 2006), a Monin-Obukhov similarity surface layer, and the Noah land surface model (Tewari et al., 2004). The urban parameterization was not enabled, in order to avoid double counting of the urban canopy effect which is treated by PALM-USM. The configuration of the WRF model corresponds to the prediction system routinely operated by the Institute of Computer Science of the Czech Academy of Sciences. ${ }^{6}$

The output of the WRF model was compared to measurements from the four Prague stations (see Sect. 3.1.1). The overall agreement between the simulated values and the observations is reasonable and corresponds to long-term evaluations done earlier. For the period of 1-5 July (see Fig. S1), WRF shows a cold bias. The largest bias occurs in the urban Prague, Klementinum station (city centre), which is as expected given the urban parameterization not being enabled in the WRF model. On the other hand, the comparison with Prague, Kbely station (closest background station to the area of interest), shows only a small bias (see also the time series in Fig. S2). Also, the comparison with vertical profiles of temperature from Prague, Libuš station, shows good agreement (see Fig. S3). Despite the slight cold bias of the WRF simulation, we take the WRF-derived values as the best inputs available.

\subsubsection{Surface and material parameters}

Solving the USM energy balance equations requires a number of surface (albedo, emissivity, roughness length, thermal conductivity, and capacity of the skin layer) and volume (thermal capacity and volumetric thermal conductivity) material input parameters. When going to such a high resolution as in our test case $(\sim 2 \mathrm{~m})$, the urban surfaces and wall materials become very heterogeneous. Any bulk parameter

${ }^{6}$ http://medard-online.cz/ 
setting would therefore be inadequate. Instead, we opted for a detailed setting of these parameters wherever possible. To obtain these data, a supplemental on-site data collection campaign was carried out and a detailed database of geospatial data was created. This includes information on wall, ground, and roof materials and colours which was used to estimate surface and material properties. Each surface is described by material category and albedo. Categories are assigned to parameters estimated based on surface and storage material composition and thickness. The parameters of all subsurface layers of the respective material were set to the same value. The parameters $C_{0}$ and $\Lambda$ (see Eqs. 1 and 2) of the skin layer are inferred from the properties of the material near the surface, which may differ from the rest of the volume. Parameters associated with particular categories are given in Supplement Table S2. A tree is described by its position, diameter, and vertically stratified leaf area density. Building heights were available from the Prague 3-D model, maintained by the Prague Institute of Planning and Development. ${ }^{7}$ All descriptions of surfaces and materials and their properties were collected in GIS formats and then preprocessed into the USM input files corresponding to the particular domain set-up.

\subsubsection{Anthropogenic heat}

Anthropogenic heat sources for our particular case are dominated by heat from fuel combustion in cars (see also the discussion in Sect. 4). Based on Sailor and Lu (2004), we assume the average heat release to be $3975 \mathrm{~J}$ per vehicle per metre of travel. Traffic intensities and hourly traffic factors are based on the annual traffic census data. The traffic intensities vary for different arms of the crossroads and traffic directions. The total count of vehicles passing through the crossroads is 12000 vehicles per day, and the intensity of the busiest road (western arm of the west-east street) is 6000 vehicles per day. The heat produced by the cars along their trajectories is released into the first model layer and spatially distributed into the model grid cells that correspond to the traffic lanes. Temporal distribution is done using prescribed hourly factors. The time factors are the same for all traffic lanes. Values of anthropogenic heat are $42 \mathrm{Wm}^{-2}$ on average (spatially and temporally), while the maximum value is $142 \mathrm{~W} \mathrm{~m}^{-2}$ (busiest road arm, peak hour). Those values refer to heat fluxes directly above the traffic lanes. The mean daily traffic heat flux averaged over the entire domain is $2 \mathrm{~W} \mathrm{~m}^{-2}$. The daily course of the traffic heat release is plotted in Fig. 4. It has been shown before that for this particular case (with strong solar irradiance, high temperatures, and only moderate traffic) the inclusion of anthropogenic heat from transportation does not result in a noticeable change in temperatures and heat fluxes (Juruš et al., 2016).

\footnotetext{
${ }^{7}$ http://www.geoportalpraha.cz
}

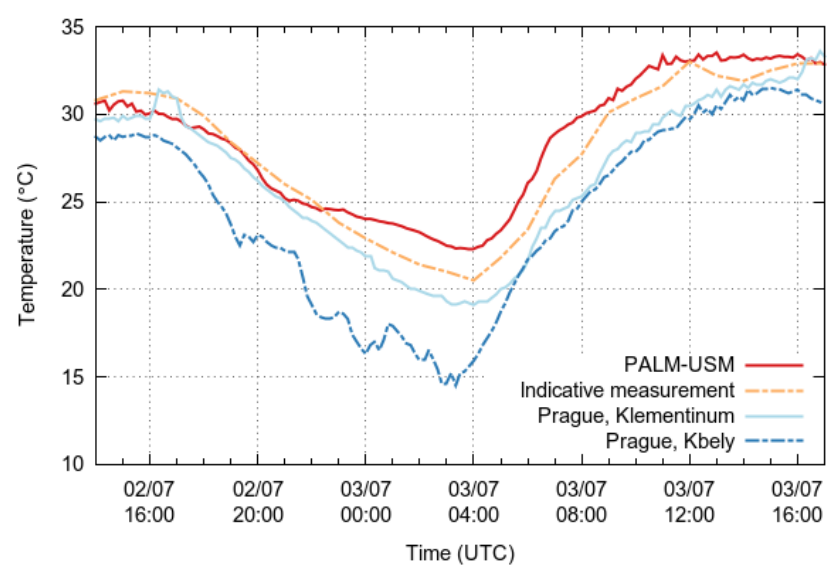

Figure 6. Air temperatures obtained from PALM-USM for location 1 in comparison to measured temperatures.

\subsection{Evaluation of PALM-USM}

First we compare the air temperatures from PALM-USM to the measurements taken during the observation campaign. Figure 6 shows the air temperature course calculated by the PALM-USM at observation location 1 at $2 \mathrm{~m}$ above ground. This temperature is compared to the indicative measurement taken at the same place and also to automatic weather stations Prague, Klementinum, and Prague, Kbely. The indicative measurement together with station Prague, Klementinum, represent the conditions inside the urban canopy, and as such, the results of PALM-USM should correspond to those values. Prague, Kbely station is plotted as a representative of the outskirts of the city. The UHI effect is clearly visible, especially at night, when the temperature outside of Prague drops down to $15^{\circ} \mathrm{C}$, while on the street level, it drops to $20^{\circ} \mathrm{C}$ only. This effect is less pronounced during the day, when the temperature difference is only $2-3^{\circ} \mathrm{C}$. This reflects the known fact that the UHI is basically a nighttime effect (Oke, 1982). The street-level air temperature as simulated by PALM-USM is in agreement with both measurements during the daytime of 2 July, but starting from 21:00 UTC, the decrease in the modelled temperature weakens, gradually leading to overestimations of up to $2{ }^{\circ} \mathrm{C}$ in the morning of 3 July.

The vertical structure of the potential temperature from PALM-USM is shown together with radiosonde observations from station Prague, Libuš, in Fig. 7. As this is a suburban background station (10 km away), the profiles are not truly comparable, especially near the surface, where effects of the UHI are expected in the PALM-USM data. The Libuš profiles are considered here mainly as a representation of the general meteorological situation in the area of interest.

From Fig. 7 it is clearly visible that PALM-USM was able to reproduce the diurnal temperature cycle of the boundary layer reasonably well. During daytime, a convective boundary layer (CBL) develops that reaches depths of about $2 \mathrm{~km}$, which is somewhat higher than the observed boundary layer, 


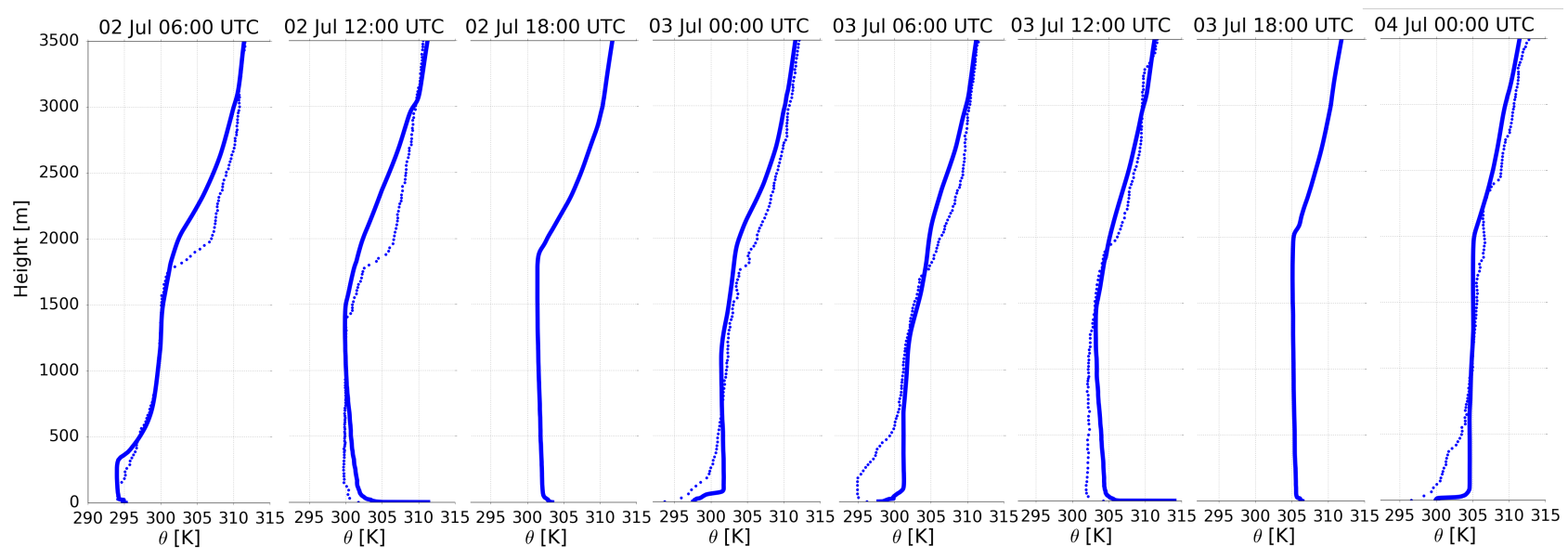

Figure 7. The vertical profiles of potential temperature modelled by PALM (solid line) and supplemented by radiosonde observations from station Prague, Libuš (except for hour 18; dotted line). Displayed are profiles from 2 July, 06:00 UTC to 4 July, 00:00 UTC with a 6 h time step.

particularly on 2 July (12:00 UTC). This can be attributed to the higher amount of heat released by the surfaces of densely built-up urban areas, as compared to the surfaces of suburban regions where the radiosonde was released. Moreover, it is visible that the potential temperature profile produced by PALM-USM displays an unstable stratification throughout the CBL on both days, while the observations show the expected nearly neutral profile. We will later see that this is an effect of the limited horizontal model domain that inhibits the free development of the largest eddies and thus is limiting the vertical turbulent mixing of warm air from the surface and relatively cold air from above. The result is an unstable layer with somewhat overly high near-surface temperatures.

During nighttime, a stable boundary layer developed in both LES and observations (due to nocturnal radiative cooling). As expected, this cooling is more rigorous in the (suburban) measurements, so that the stable layer was able to extend to heights of $500 \mathrm{~m}$, whereas PALM-USM predicts a stable layer of not more than $100 \mathrm{~m}$ vertical extent (see 00:00 UTC on 3 and 4 July). This result is in agreement with what was already shown in Fig. 6 and is a known feature of the UHI (Oke, 1982).

Figure $8 \mathrm{a}-\mathrm{c}$ shows the temporal development of the turbulence, which is here represented by the variance of vertical velocity. The diurnal turbulence cycle is very clearly visible, with maximum intensities of $1.4 \mathrm{~m}^{2} \mathrm{~s}^{-2}$ around noon located in the well-mixed part of the boundary layer (Fig. 8c). Ideally, it would show a clear maximum in the middle of the boundary layer, but two processes avoid this. First, the urban canopy arranges the release of heat at different heights above the ground surface, and second, the limited horizontal model domain does not allow for a free development of turbulence. Figure 8a further shows that the turbulence immediately starts to decay after sunset, which is accompanied by the development of a stable boundary layer near the sur- face (not shown here). During nighttime, the turbulence further decays and the maximum values of the variance reduce to $0.3 \mathrm{~m}^{2} \mathrm{~s}^{-2}$. Due to the continuously heating urban surface layer, however, turbulence is kept alive until the next morning (see also Fig. 8a).

Next, in order to assess how well the model is able to model the energy transfer between material and atmosphere, we compare modelled values to on-site measurements of surface temperatures captured by the infrared camera. Here we present results from five selected locations, chosen to cover wall orientations to all cardinal directions and the ground: location 3 (south-facing wall) in Fig. 9, location 4 (west-facing wall) in Fig. 10, location 7 (north-facing wall) in Fig. 11, location 9 (east-facing wall) in Fig. 12, and location 8 (ground) in Fig. 13. Corresponding surface and material parameters for all evaluation points can be found in Tables S2 and S3 in the Supplement. Results for all nine locations are also displayed in the Supplement (Figs. S4-S12). In general, PALMUSM captures the observed daily temperature patterns very well. The temperature values during the daytime are captured reasonably well, while the model slightly overestimates nighttime temperatures.

Figure 9 shows a south-facing wall in the western arm of the west-east street measured from location 3 . We evaluated the model performance in four points. All points are assigned the same material category (plastered brick wall; see Tables S2 and S3). Points 1, 2, and 3 are on a surface with the same colour, which is represented by an albedo of 0.2 in the model. Point 4 is placed on a surface of lighter colour (albedo of 0.7). The lighter surface colour in point 4 results in a significantly lower measured peak temperature of $6-9{ }^{\circ} \mathrm{C}$ less than in other points. The model correctly captures the lower temperature in point 4 , although the modelled maximum in point 4 is a bit higher than the measured maximum. The effect of different albedos can be seen in Fig. 13 


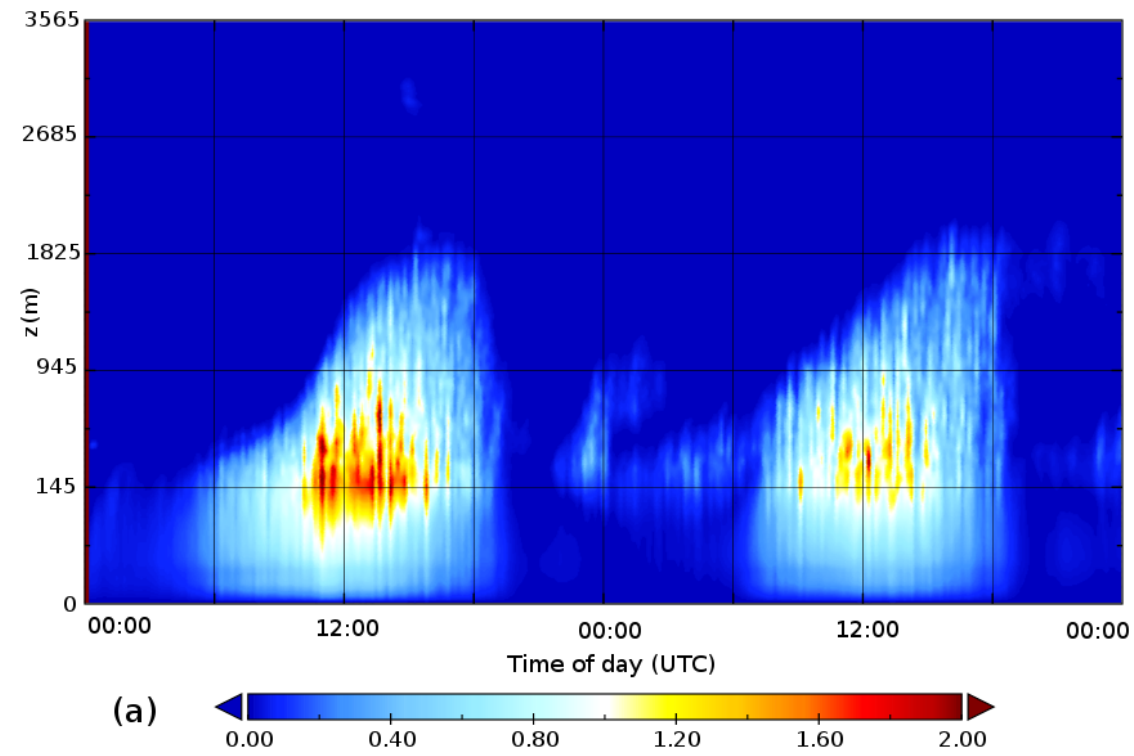

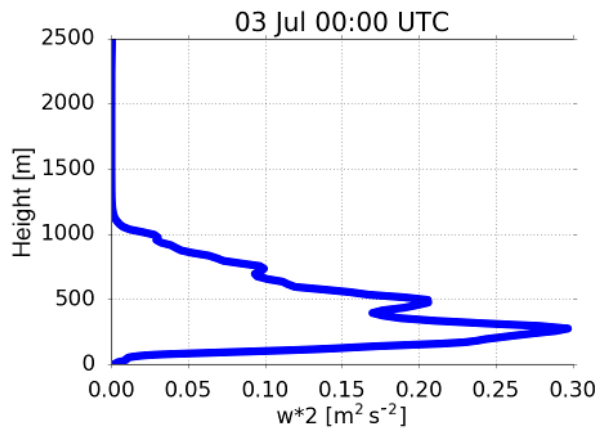

(b)

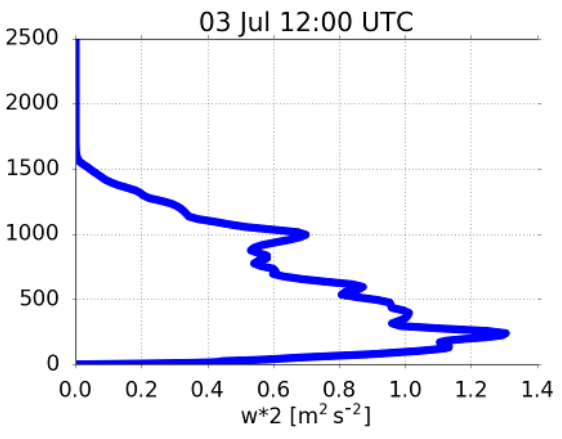

(c)

Figure 8. (a) Time-height cross section of the variance of the vertical velocity component (top), and vertical profiles of the same quantity at two selected times: (b) 3 July 00:00 UTC and (c) 3 July 12:00 UTC (bottom).

for points 2, 3, and 4, too. The observation that the model overestimates values at some evaluation points located in the lowest parts of the buildings can also be made at other observation locations (see location 4, Fig. 10, point 1, or location 5, Fig. S8, point 1).

In Fig. 9, daytime temperatures of points 1 and 2 are captured quite well, while the model overestimates the temperature in point 3 . In reality, this point is shaded by an alcove until 08:10 UTC (see the IR picture in Fig. S13) and thus it is irradiated approximately $1 \mathrm{~h}$ later than point 1 . As a consequence, the increase in its temperature is delayed and the reached maximum temperature is $4{ }^{\circ} \mathrm{C}$ lower than in point 1 . This facade unevenness is not resolved by the topography model in PALM and it thus predicts the same values for points 1 and 3 .

Figure 10 shows the same comparison for a west-facing wall in the southern arm of the north-south street measured from location 4 . The temperature course in point 7 demonstrates the effect of surface shading by a tree that ob- structs the solar radiation at this location between 13:10 and 14:50 UTC. This leads to a decrease in surface temperature between 13:00 and 15:00 UTC, whereas the surface temperature at the other points keeps increasing. This shading effect can also be seen in Fig. 12 for point 5, which is shaded by a tree between 06:15 and 08:15 UTC. Both cases are correctly represented by the model. Another illustration of tree shading is in Fig. S14.

The results for a north-facing wall in the eastern arm of the west-east street are shown in Fig. 11. In contrast to other walls, where daytime temperatures are captured quite well, we can see that for north-facing walls the model systematically overestimates the surface temperature (the same behaviour can be observed at another north-facing wall observed from location 2, Fig. S5). This effect emerges when the opposite walls are fully irradiated by the Sun (Fig. 11, 08:00-14:00 UTC). The same observation can be made for east-facing walls in the afternoon hours (Fig. S8, 12:00- 

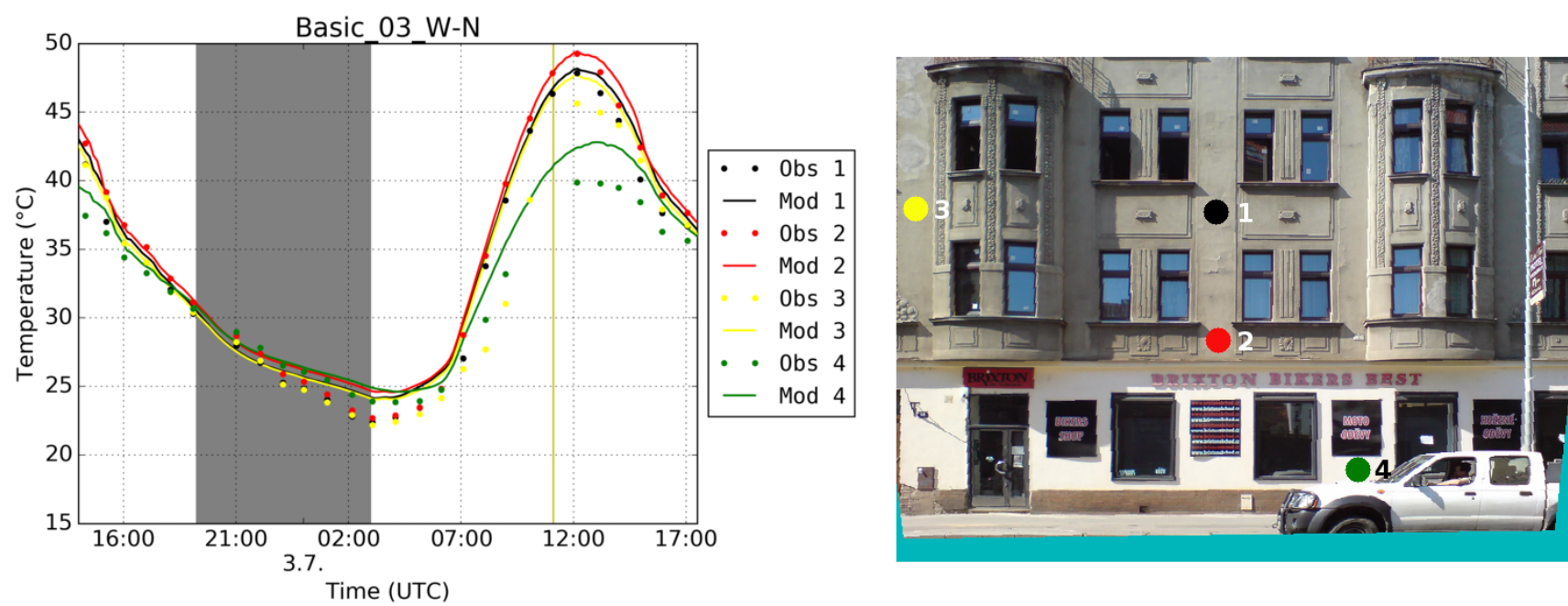

Figure 9. Comparison of modelled and observed surface temperatures from observation location $3\left(50.10354^{\circ} \mathrm{N}, 14.45006^{\circ} \mathrm{E}\right)-\mathrm{view}$ of the south-facing wall. The graph shows comparisons for selected evaluation points for the period of the observation campaign from 2 July 2015 , 14:00 UTC to 3 July 2015, 17:00 UTC. The solid line represents modelled values, while the dots show the observed values. The shaded area depicts nighttime and the yellow vertical line depicts solar noon.
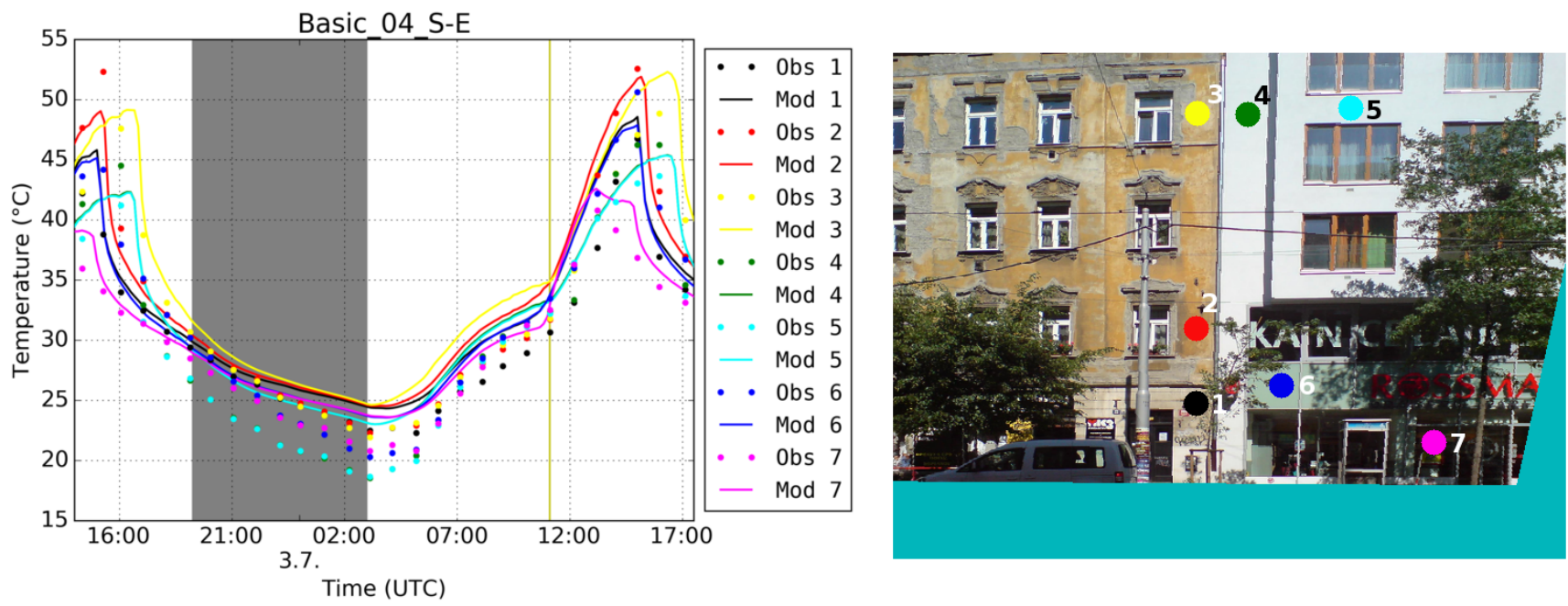

Figure 10. As for Fig. 9 for location $4\left(50.10288^{\circ} \mathrm{N}, 14.44985^{\circ} \mathrm{E}\right)-$ view of the west-facing wall.

15:00 UTC). The possible reason for this overestimation is discussed later in Sect. 4.

Figure 12 shows the east-facing wall of the northern arm of the north-south street. We can observe the effect of shading by opposite buildings here. As the Sun rises and the shade cast by opposite buildings moves downward in the morning, the Sun gradually irradiates points 3 (from 04:45 UTC), 2 (from 05:40 UTC), and 1 (from 06:10 UTC). This is reflected in observations and also in model results, although the modelled temperature in point 3 starts to increase somewhat later than the observed temperature at the same point due to the discretized geometry of the buildings on the opposite side of the street. The effect of the shading of east-facing walls during the sunrise is further visible in Fig. 15.
Finally, Fig. 13 shows the measurement of the ground surface temperature. The model captures the maximum values well, which are higher for asphalt (points 2, 3, and 4) than for paving blocks (points 1, 5, 6, and 7). The lower temperature of the white crosswalk, represented in the model as a one-grid-width belt with higher albedo, is reflected in the model results as well. Also, the time when the temperature starts to increase in the morning is captured with some minor discrepancies, owing to the discretized representation of the surrounding buildings.

Figure 14 shows a view of the surface temperatures for the entire modelling domain on 3 July at 12:00 UTC, demonstrating different heating of facades due to different surface and material properties. As seen for all similarly irradiated 


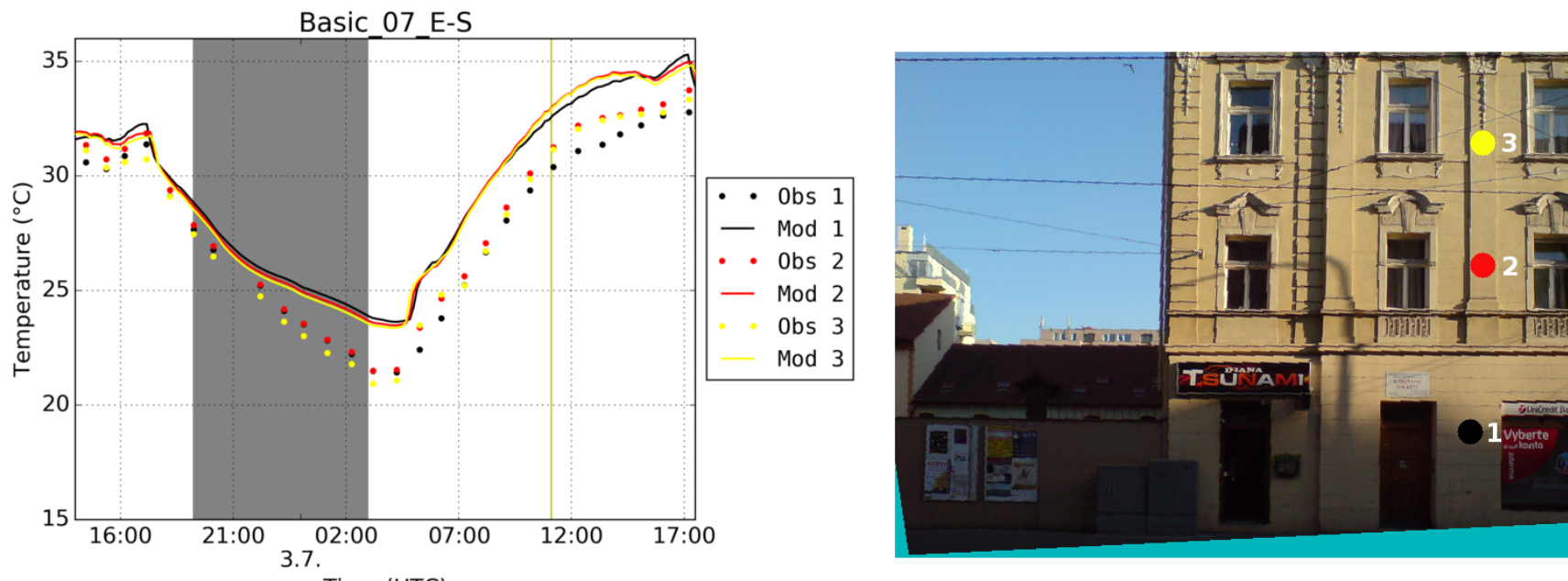

Figure 11. As for Fig. 9 for location $7\left(50.10329^{\circ} \mathrm{N}, 14.45040^{\circ} \mathrm{E}\right)$ - view of the north-facing wall.
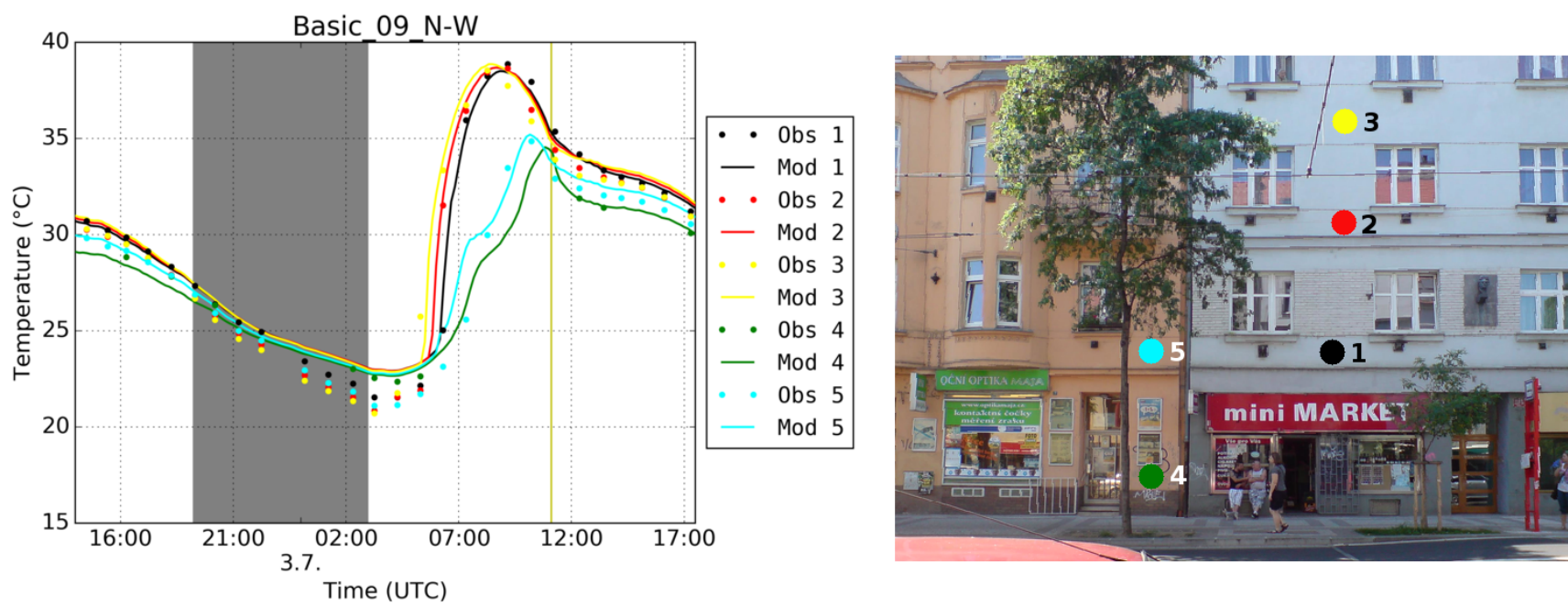

Figure 12. As for Fig. 9 for location $9\left(50.10354^{\circ} \mathrm{N}, 14.45006^{\circ} \mathrm{E}\right)$ - view of the east-facing wall.

surfaces (e.g. all south-facing walls), the different wall properties lead to differently warmed surfaces. Further, cool spots resulting from shading by trees are clearly visible. This view also demonstrates the effect of transforming the real urban geometry into the regular modelling grid. The detailed view of east-facing walls in the north-south street in the morning of 3 July is shown in Fig. 15. This picture shows surface temperatures after the sunrise at 06:00 and 08:00 UTC. The view displays the effects of shading by buildings on the opposite side of the street as well as the thermal inertia of the material and the impact of different material properties.

\subsection{Sensitivity tests}

\subsubsection{Sensitivity to the dynamics of surface heat fluxes}

In order to show the effect of dynamically calculated surface heat fluxes that are derived by the USM depending on given material properties, we performed another simulation with disabled USM (PALM noUSM). In order to make both simulations comparable, they need to be based on the same energy input. This is achieved by prescribing a homogeneous surface heat flux to all surfaces (ground, roof, wall) in the noUSM set-up, with this heat-flux value derived from the original USM simulation as the average over all surfaces in the entire domain in the target time. Simulation parameters in the noUSM simulation were set to values of the original USM set-up from the selected period. The noUSM simula- 

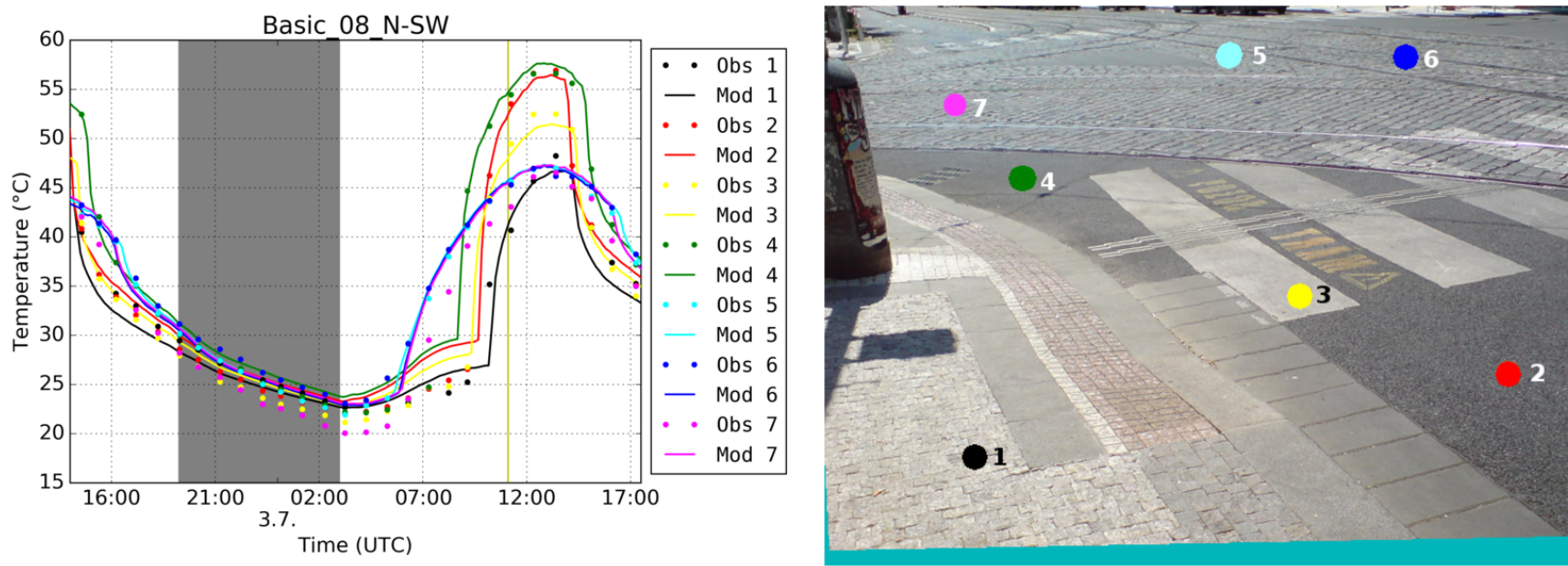

Figure 13. As for Fig. 9 for location $8\left(50.10340^{\circ} \mathrm{N}, 14.45007^{\circ} \mathrm{E}\right)-$ view of the ground on the crossroads.

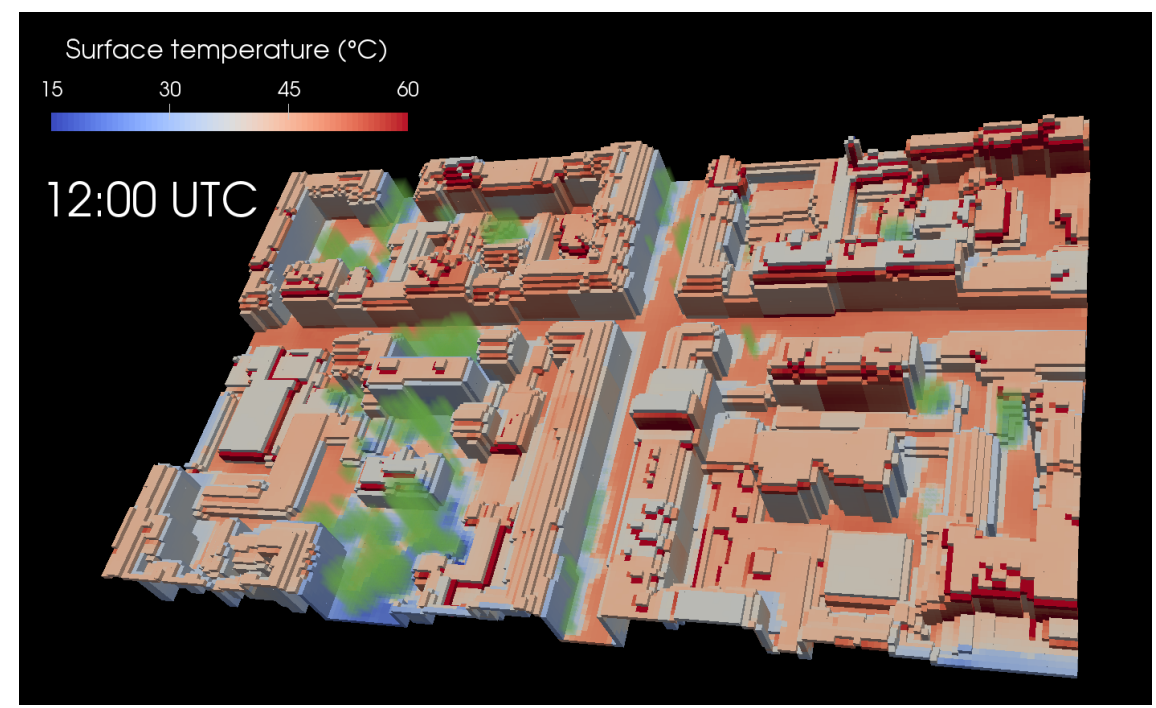

Figure 14. Modelled surface temperatures for the entire domain on 3 July at 12:00 UTC. Green areas represent vegetation (trees).

tion ran for $5 \mathrm{~h}$ to reach a quasi-steady state. Figure 16 shows the horizontal cross section of the time-averaged $(1 \mathrm{~h})$ vertical velocity at $10 \mathrm{ma}$ a.g. 1 . Figures correspond to simulation time 3 July at 14:00 UTC, when west- and south-facing walls were fully irradiated and heated up by the Sun. The wind above the roof top was north-west and its strength was about $2 \mathrm{~ms}^{-1}$. In the PALM-noUSM case, a typical vortex perpendicular to the street axis in the west-east oriented street and in the southern part of the south-north oriented street was formed. In the reference case, however, the non-uniform heat flux was heating the air on the south- and west-facing walls, changing the strength of the street vortex. This effect is more intensely pronounced in the southern arm of the northsouth oriented street where the strong vortex observed in case PALM-noUSM has significantly weakened. In Fig. 17 it becomes evident that the entire flow circulation pattern within this street arm had changed, leading to a change in the vortex orientation.

The accurate prediction of the canyon flow is an essential prerequisite, among others, for the accurate prediction of pollutant concentrations at street level and their vertical mixing. Our results - in line with previous studies - show that an interactive surface scheme is a crucial part of the urban modelling system and alters the canyon flow significantly.

\subsubsection{Sensitivity to material parameters}

Gathering of properties of individual materials and surface types is a challenging task. For our case, materials were categorized, and representative parameters were assigned to each category. The only exception is the albedo which was set individually for each particular surface based on surface colour. 


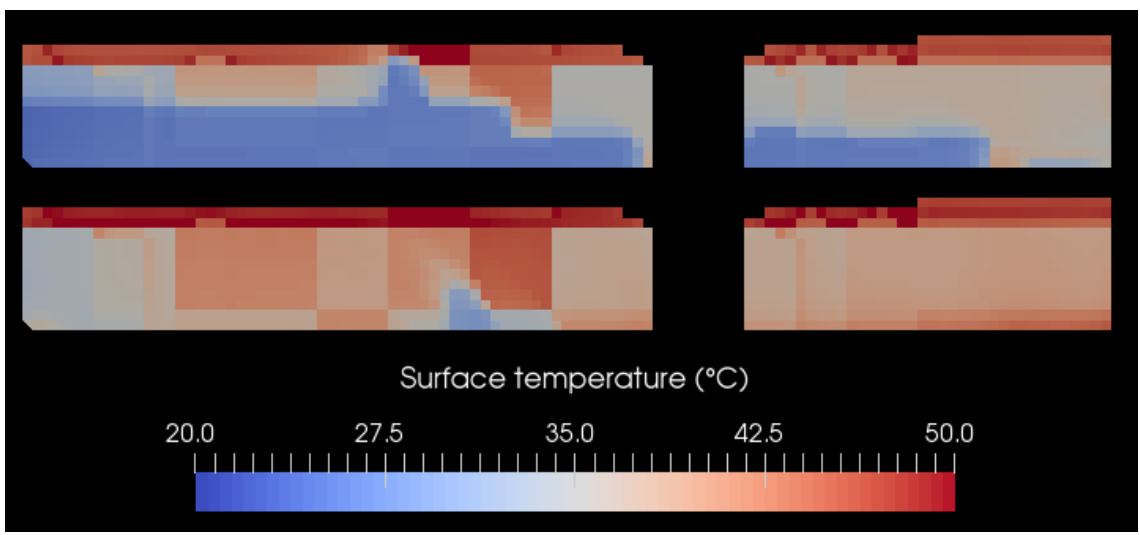

Figure 15. Modelled surface temperatures of the east-facing walls in the north-south street after the sunrise on 3 July at 06:00 UTC (top) and 08:00 (bottom) UTC.
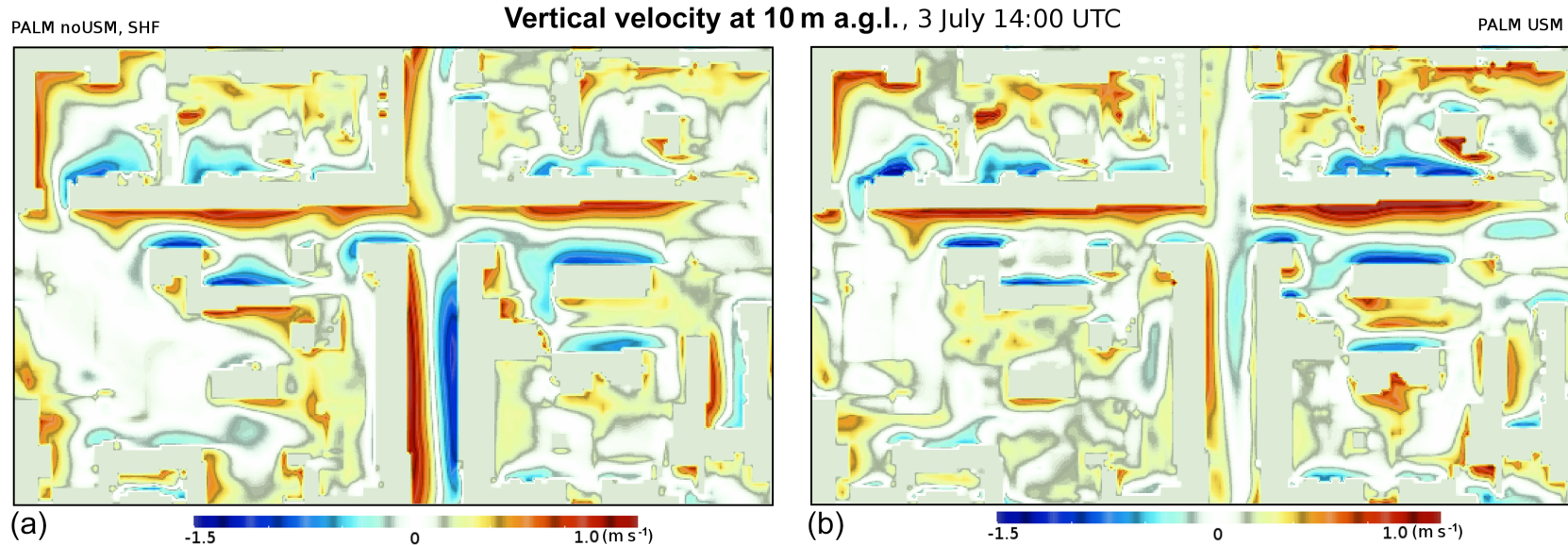

Figure 16. Horizontal view of modelled vertical velocity (1 h average) at $10 \mathrm{~m}$ a.g.1. on 3 July, 14:00 UTC. (a) presents a stationary simulation without USM with constant surface heat fluxes and (b) the reference simulation with USM enabled.

The uncertainty of the input parameters is high, though. In order to estimate related uncertainties of model results, a series of simulations was performed where one parameter was changed per simulation. The tests included the increase and decrease in albedo, the thermal conductivity of both the material and the skin layer, and the roughness length of the surface. The albedo was modified by \pm 0.2 and all other parameters were adjusted by $\pm 30 \%$ of their respective value. The sensitivities of the surface temperature at selected locations and evaluation points are presented in Fig. 18. The largest changes in model output are generally observed during daytime. The model behaves according to the physical meaning of the parameters: decreased roughness lowers turbulent exchange of heat between the surface and air, leading to the increase in surface temperature when the air is colder, which is usually the case in our simulation. A decrease in roughness to $70 \%$ leads to the increase in temperature by up to $4^{\circ} \mathrm{C}$. A decrease in thermal conductivity leads to more intense heating of the surface when the net heat flux is positive (usually during daytime) and to less intense cooling when it is negative (usually during night). The decrease in the albedo leads to higher absorption of SW radiation and an increase in the surface temperature during daytime. The sensitivity of the modelled surface temperature can reach up to $5{ }^{\circ} \mathrm{C}$.

This sensitivity analysis shows that even moderate changes in the wall material properties can lead to differences in the surface temperatures of a few degrees Celsius. As mentioned in Sect. 3.3, we observe an overestimation at some evaluation points located at the lower parts of the buildings (location 3 , point 4 ; location 4 , point 1 ; location 5 , point 1 ). We hypothesize that a possible reason can be that walls at lower parts of buildings can be built from different material than the upper floors. In that case the thermal conductivity used in the model would be different than its true value. This can be the possible explanation for some discrepancies between model and observation. On the other hand, some discrepancies (e.g. overestimation of temperatures on north-facing walls) are systematic and they can probably be attributed to 


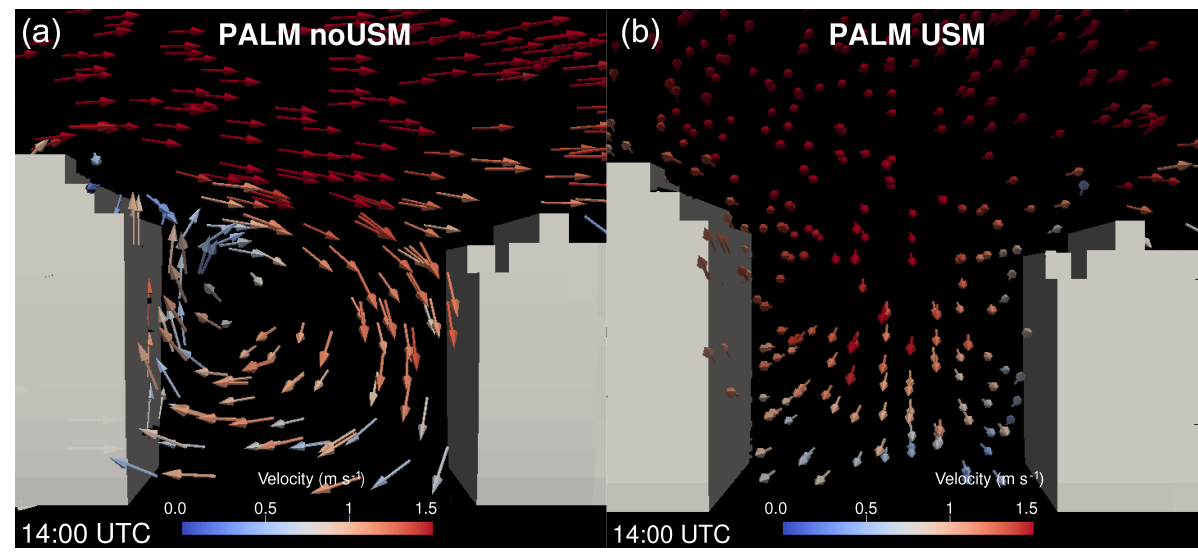

Figure 17. Wind field. Simulation without USM with prescribed surface heat fluxes (a) and with USM (b). View from the southern border of the domain towards the crossroads.

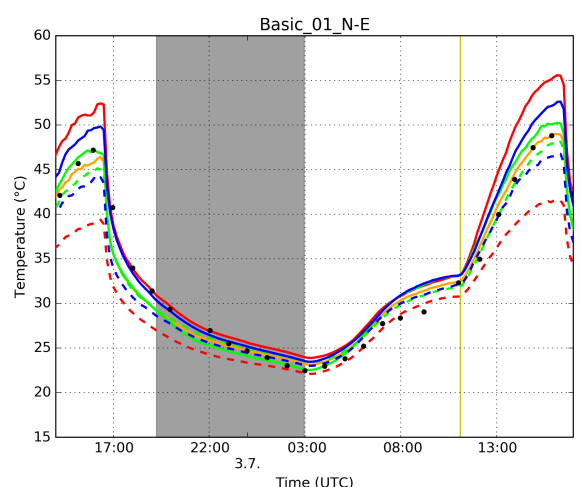

(a)

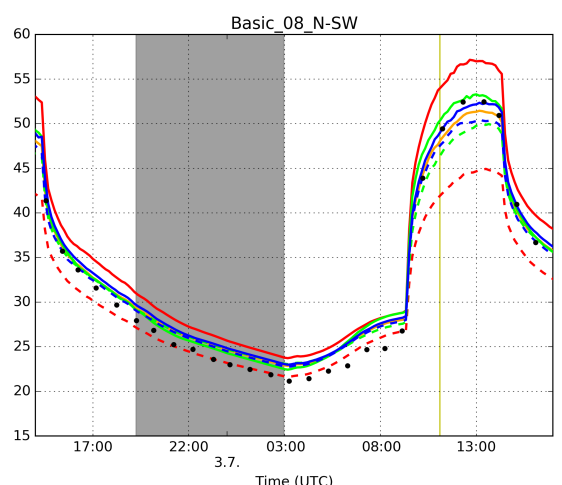

(b)

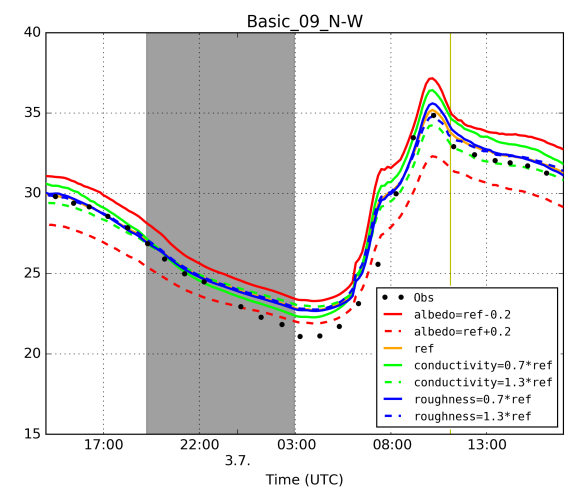

(c)

Figure 18. The sensitivity of PALM-USM to changes in surface and material parameters: (a) for the west-facing wall measured from location 1 for evaluation point 1 , (b) for the ground measured from location 8 for evaluation point 3, and (c) for the east-facing wall measured from location 9 for evaluation point 5. ref is the reference run; other lines correspond to the increase (dashed line) and decrease (solid line) in the respective parameters with respect to the reference run: albedo was increased/decreased by 0.2 , thermal conductivity of materials and skin surface layer (conductivity) was increased/decreased by $30 \%$, and so was the roughness length (roughness). Obs is the measurement in the evaluation point.

some limitation of the set-up, or the model itself. Some possible reasons are discussed in Sect. 4.

\section{Discussion}

The deficiencies in the model's description of reality and the discrepancies against observations may arise from limitations, simplifications, and omissions within the model itself and from limited exactness, representativity, and appropriateness of the model set-up.

\subsection{Limitations of the model}

The USM and its radiative transfer model (RTM) assume only a diffuse reflection and do not treat windows. In our configuration, specular reflection can play a role for glossy surfaces like flagstones and glass. Windows also transmit part of the radiation into the building and only the rest is absorbed by the glass itself. Examples of IR camera observations of the south-facing wall taken from location 6 at 01:08, 10:08, and 13:17 UTC are shown in Fig. S15. The effective temperature of the window is usually lower by several $\mathrm{K}$ to a few tens of K compared to the surrounding wall. Since this is not captured by the model, the longwave radiative flux emitted from those walls can be overestimated. The approximate calculation for the area captured by these IR photos shows that average heat fluxes of the wall with windows are lower by $7 \mathrm{~W} \mathrm{~m}^{-2}$ (01:08 UTC), $27 \mathrm{~W} \mathrm{~m}^{-2}$ (10:08 UTC), and $25 \mathrm{~W} \mathrm{~m}^{-2}$ (13:17 UTC), as compared to the wall without windows. The difference in the average effective temperature of the wall is $1.5,4$, and $3.5 \mathrm{~K}$, respectively. As mentioned in Sect. 3.3, the model overestimates the temperature of north-facing walls. Since the modelled net radiation on the north-facing walls ranges from $-20 \mathrm{~W} \mathrm{~m}^{-2}$ during night up 
to $70 \mathrm{~W} \mathrm{~m}^{-2}$ during the day, and since the opposite walls represent about one-third to half of the visible area, these differences are not negligible and may be responsible at least partly for the overestimation of the surface temperature of northfacing walls. This suggests that an extension of the USM by a proper window model is very desirable.

The RTM also simulates only a finite, configured number of reflections. After that, the remainder of reflected irradiance is considered fully absorbed by the respective surface. The amount of absorbed residual irradiance is available among model outputs and it can be used to find an optimum number of reflections until the residual irradiance is negligible. The optimum setting depends on the albedo and emissivity of the surfaces. In our set-up, the residual irradiance was below $1 \%$ of the surface's total at most surfaces after three reflections, and it was negligible after five reflections.

The current version of the RTM model does not simulate absorption, emission, and scattering of radiation in the air within the urban canopy layer; thus, it is not suitable for modelling of situations with extremely low visibility like fog, dense rain, or heavy air pollution. However, under clear air conditions and in an urban set-up where typical distances of radiatively interacting surfaces are of the order of metres or tens of metres, these processes are negligible ${ }^{8}$. Most of the solar radiation's interaction with the atmosphere happens on the long paths from top of atmosphere to ground and during the interaction with clouds, i.e. above the urban layer, where the method of modelling of these processes depends on the selected solar radiation model in PALM.

The USM is currently coupled to PALM's simple clear-sky radiation model, which provides only limited information on sky longwave radiation, and it does not provide air heating and cooling rates. This limitation will be overcome in the near future when the USM will be coupled to the more advanced RRTMG model in PALM.

Shading by plant canopy is only modelled for shortwave radiation; in the longwave spectrum, the plant canopy is considered fully transparent. Typical daily maxima of SW radiative fluxes (mostly from direct solar radiation) are much higher than maxima of LW fluxes. Moreover, much of the LW heat exchange is compensated when surfaces are near radiative equilibrium. Therefore, for the $\mathrm{LW}$ shading by plant canopy to cause significant changes in the heat fluxes, two conditions must occur simultaneously: the plant canopy and the affected surface have to occupy a large portion of each other's field of view (e.g. a large and dense tree close to a wall); and the temperature of the plant canopy, the affected surface, and the background field of view have to differ significantly (e.g. the wall is under direct sunlight and the plant canopy is shaded or cooled by convection).

\footnotetext{
${ }^{8}$ Using MODTRAN (Berk et al., 2014) for a clean-air summer urban atmosphere, transmissivity for $10 \mu \mathrm{m}$ radiation (i.e. peak wavelength of black-body radiance at $300 \mathrm{~K}$ ) per $1 \mathrm{~km}$ of air is approximately 0.85 , which equals 0.998 per $10 \mathrm{~m}$.
}

To illustrate the amount of affected heat flux, let us propose a simple realistic scenario where these effects are very strong. Let us have two opposing walls, each occupying $50 \%$ of the other's field of view (without regard for plant canopy), and let us add a row of trees directly between the walls, blocking $30 \%$ of the mutual radiative exchange between the walls. Let the temperature of the ambient air, one of the walls, and the plant canopy be $300 \mathrm{~K}$, and let the other wall heat to $320 \mathrm{~K}$ due to strong direct sunlight.

Under these conditions, the cool wall would be receiving $68 \mathrm{~W} \mathrm{~m}^{-2}$ of excess total radiative flux (absorption minus emission) due to the opposing wall being hotter. The hot wall would be losing the same excess total flux due to the opposing wall being cooler, both when not accounting for shading by plant canopy. With the plant canopy, the cool wall would only be receiving $41 \mathrm{~W} \mathrm{~m}^{-2}$ of excess total flux from the opposing wall and the remaining flux of $21 \mathrm{~W} \mathrm{~m}^{-2}$ would be absorbed by the plant canopy. The hotter wall would experience the same radiative cooling as without plant canopy.

With regard to our test scenario, we accepted the simplification, considering that the demonstrated omission would affect only a few spots in the modelled domain. Modelling of LW interaction with plant canopy is planned for the next version of the model.

Plant leaves are treated in the USM as having zero thermal capacity and a similar temperature to the surrounding air. Any radiation absorbed by leaves directly heats the surrounding modelled air mass. In reality, plant leaves are thin, they have a large surface area, and they readily exchange heat with air. This simplification is common among radiative transfer models (see e.g. Dai et al., 2003) and it is also in accordance with the current implementation of the non-urban plant canopy model in PALM.

Evapotranspiration of the plant canopy is not modelled and surfaces are considered impervious to water. Generally, these are important processes which will be accounted for in the upcoming versions of the model. The importance of evapotranspiration and latent heat grows with the modelled proportion of vegetation. The measurements in Grimmond and Oke (1999) - specifically in Table 2, p. 925 - show that in their case, latent heat flow vs. net radiation ratio ranged from $4 \%$ in the downtown area (similar to the streets in our test case) up to $37 \%$ in the suburban area with a high fraction of vegetation. In our case, however, street surfaces are covered by asphalt or granite paving blocks with gaps filled by asphalt. Only a part of the pavements in the north-south street that are paved with limestone blocks can be considered pervious to water to a larger extent. There are only a few trees in the streets, concentrated mostly in the north-south street, and their treetops are not very dense (Figs. 12 and 10). Moreover, the last precipitation before the observation campaign was recorded in Prague on 29 June $\left(0.3 \mathrm{~mm} \mathrm{day}^{-1}\right)$. Therefore, it can be expected that the neglect of these processes will not have large effects on the evaluation presented in this article. 


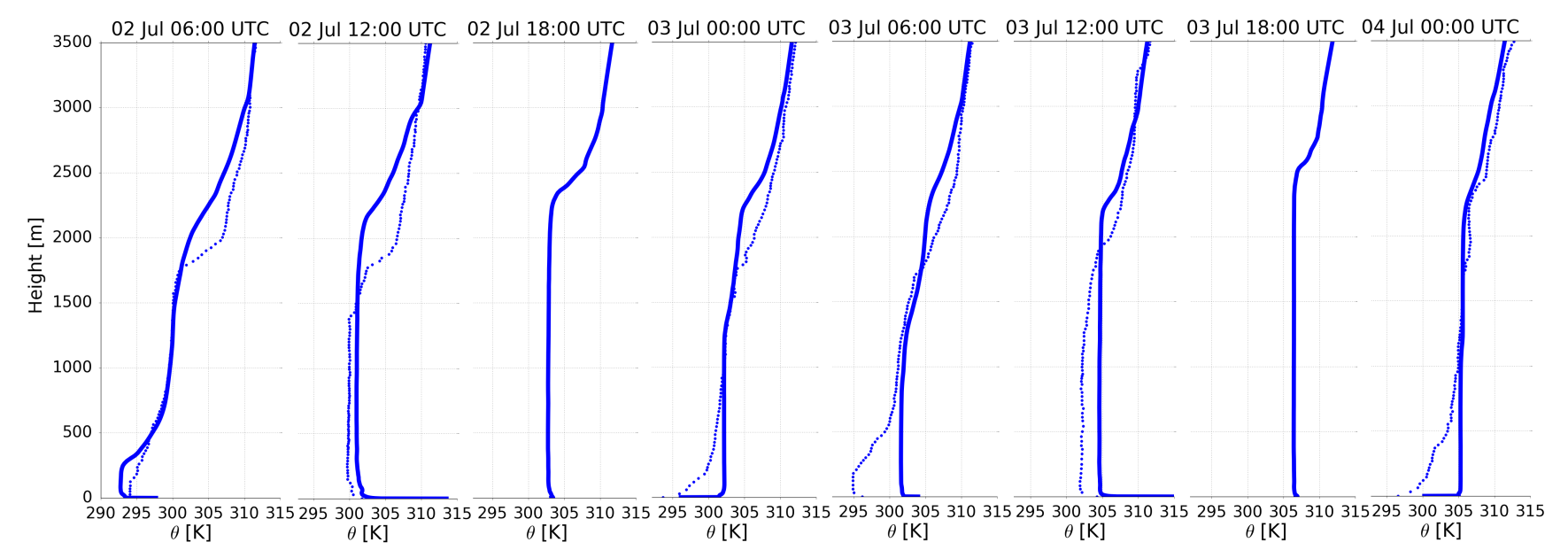

Figure 19. As for Fig. 7 for the idealized simulation with an enlarged domain (see Sect. 4).

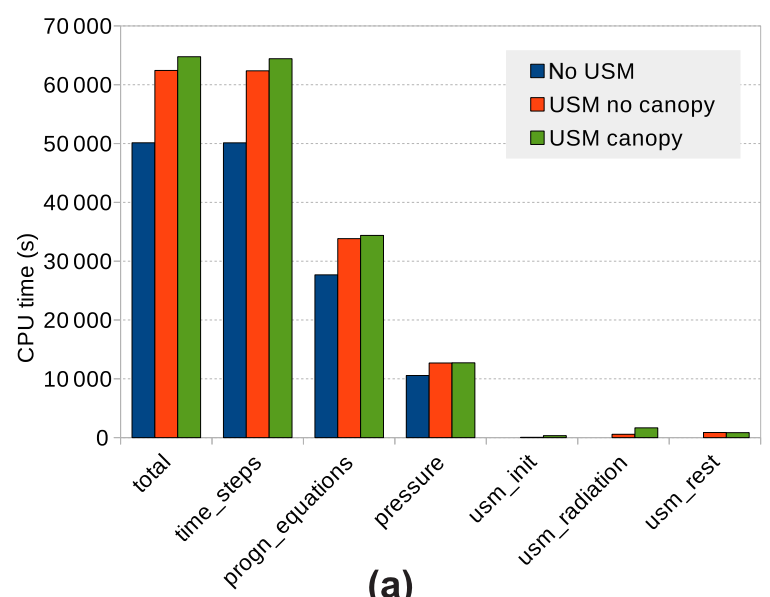

(a)

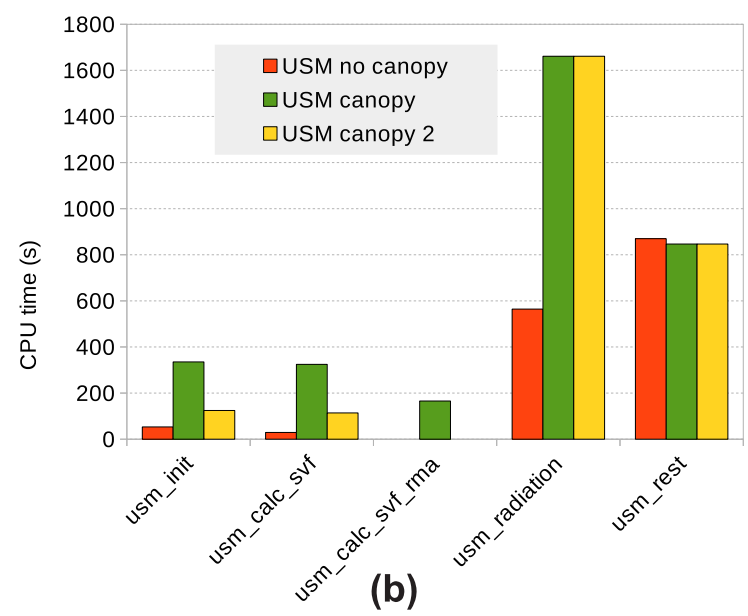

Figure 20. Comparison of the duration of the model run and the time spent in the chosen subprocesses of the model (a) and detailed comparison of parts of the USM model (b). Meaning of data series: "no USM" the run of PALM with USM switched off, "USM no canopy" the run with USM with no plant canopy, "USM canopy" run with USM and plant canopy, and "USM canopy 2" the same run with the model configuration option usm_lad_rma turned off. Meaning of items: total - total CPU time of the model run; time_steps - time spent in time stepping; progn_equations - evaluation of all prognostic equations; pressure - pressure calculation; usm_init - initialization routines of USM; usm_radiation - calculation of the USM radiation model; usm_rest - remaining USM processes (particularly energy balance and material thermal diffusion); usm_calc_svf - calculation of SVF and CSF; usm_calc_svf_rma - time spent with one-sided MPI communication. The set-up of the model corresponds to the set-up described in Sect. 3.2 with a reduced number of layers to 81.

\subsection{Appropriateness of the presented set-up}

One of the potential issues of the set-up is the model domain's horizontal size. The CBL height reached values of up to $2000 \mathrm{~m}$ during daytime (see Fig. 7). It is well known that the largest structures in a CBL scale with the height of the boundary layer, and they typically form hexagonal cellular patterns. In this context, the chosen horizontal model domain is too small to resolve these structures. We must thus expect that the largest turbulent eddies were not able to freely develop during daytime. Nevertheless, the feedback of these eddies onto the surface-subsurface continuum can be regarded as small. This is supported by our recent experiences using the PALM-LSM system for a dry bare-soil configuration (work in progress, not shown). Moreover, as we have seen in Sect. 3.3, the simulated skin temperatures compare well with observations and do not display significant fluctuations at turbulent timescales.

However, we have seen that the vertical profiles of potential temperature display an unusual unstably stratified shape during daytime. To estimate the possible influence of the domain extent on the mean vertical profiles, an idealized simulation was performed. The horizontal grid size was increased by a factor of 10 to $20.8 \mathrm{~m}$, while all the rest of the set-up was 
kept unchanged. This artificially increased the simulation domain to a horizontal extent of $3760 \mathrm{~m} \times 2260 \mathrm{~m}$, without having to increase the number of computational grid points. The topography of this domain is not fully comparable with the original domain as the street width is 10 times larger and the ratio of the sizes of individual grids also differs from the original set-up. Nevertheless, it can indicate the overall characteristics of the set-up with a large domain. Vertical profiles of potential temperature from this simulation are shown in Fig. 19. Compared to Fig. 7 we can see that the unstable stratification that was observed at 12:00 UTC and reached up to $1.5 \mathrm{~km}$ changed to near-neutral conditions in the largedomain simulation, corresponding to well-mixed boundary layer conditions. Based on this finding, we must be aware of the fact that the formation of the largest turbulent eddies was inhibited by the small model domain, but that they are essential for the efficient vertical transport of heat. While this is no problem for RANS-type models, where all turbulent eddies are parameterized, it imposes a limitation for the application of LES models in urban areas, as one has to ensure that the horizontal model domain is at least the size of the boundary-layer depth and thus will require enormous computational resources. However, one of the methods to overcome this problem is already under way. This is the two-way nesting system for urban applications that has already been implemented in PALM and allows for use of finer grid spacings in areas of special interest while having coarser grids in the surroundings.

Another limitation of the set-up is the fixed indoor temperature. The studied simulation spans only over 2 days with similar summer weather conditions. Considering the heat capacity of walls, the influence of changes in the indoor temperature can be regarded as small for the presented simulation. This issue could be more important for long-term simulations.

Gathering information about the detailed structure of the walls in the entire domain constitutes a significant challenge. For practical reasons, the material of every particular wall is considered homogeneous in our simulation. Thus, the thermal conductivity of the sandwich structure of insulated walls is not well represented, as well as the structure of pavements and streets. The conductivity of the entire wall structure can be substituted by the average conductivity with no effect to the long-term average heat flux going through the wall. However, layers of walls described by the same average parameters can actually have different thermal capacities and conductivities, resulting in different thermal dynamics. This can partially influence the shape of the surface temperatures in affected places.

Anthropogenic heat sources were limited to traffic in our test case. Other potentially significant anthropogenic sources can be heat emissions from buildings. Considering that the period of interest is in the summer, the relevant processes would be air conditioning, which however is not common in this part of the city.
When evaluating model results, the uncertainty of the measurements must also be taken into account. In our case, the measurements are affected by not using the emissivity correction option of the IR camera, and by possible reflections, mainly in the case of horizontal surfaces. For this reason, only those points where the influence of reflections was supposed to be negligible were considered for evaluation.

The presented evaluation of the model is limited to a specific city district and meteorological condition. However, since the model is based on general formulations, it should be applicable for arbitrary configurations of fully urbanized areas. Concerning the meteorological set-up, we suppose that the model with its current limitations is yet suitable for representing the urban surface-atmosphere interactions under meteorological conditions where the omitted processes do not play a significant role. Model limitations will be resolved in the future PALM-USM versions, which will be validated accordingly for a wider range of meteorological conditions and surface types. A key factor for a successful validation is good knowledge of these conditions and the properties of all urban surface elements.

\section{Computational aspects}

The correct functionality and computational efficiency of the implementation of USM was verified in various environments. The tested configurations varied in processor type (Intel $\left.^{9}, \mathrm{AMD}^{10}\right)$, compiler $\left(\mathrm{GNU}^{11}, \mathrm{PGI}^{12}\right.$, Intel $\left.{ }^{13}\right)$, implementation of MPI (MVAPICH2 ${ }^{14}$, IMPI ${ }^{15}$ ), and other aspects. The comparison presented in this chapter was performed on the Salomon supercomputer ${ }^{16}$ with Intel $\mathrm{C}$ and Fortran compilers and Intel MPI (2016 versions for all). The set-up of the model corresponds to the set-up described in Sect. 3.2 with a decreased number of vertical layers to 81 and 1-day simulation extent to get a reasonable computational time also for a smaller number of MPI processes.

Figure 20a shows the comparison of the total CPU time of the model run and the CPU time needed for particular chosen subroutines. Almost all of the total time is spent on time stepping. The direct expense of the USM can be split into three parts: the time spent in initialization routines of the USM at the start of the model run, the time needed for calculation of the urban radiation model, and finally the time of remaining USM processes, particularly the energy balance and the material thermal diffusion. The total increase in the calculation time with the USM switched on is about $25 \%$

\footnotetext{
${ }^{9}$ https://ark.intel.com/

${ }^{10} \mathrm{http}: / /$ www.amd.com/en-us/products/processors

${ }^{11}$ https://gcc.gnu.org/

$12 \mathrm{http}: / /$ www.pgroup.com/

${ }^{13} \mathrm{https}$ ://software.intel.com/en-us/intel-compilers

${ }^{14}$ http://mvapich.cse.ohio-state.edu/

$15 \mathrm{https}$ ://software.intel.com/en-us/intel-mpi-library

${ }^{16} \mathrm{https} / / /$ docs.it4i.cz/salomon/introduction
} 


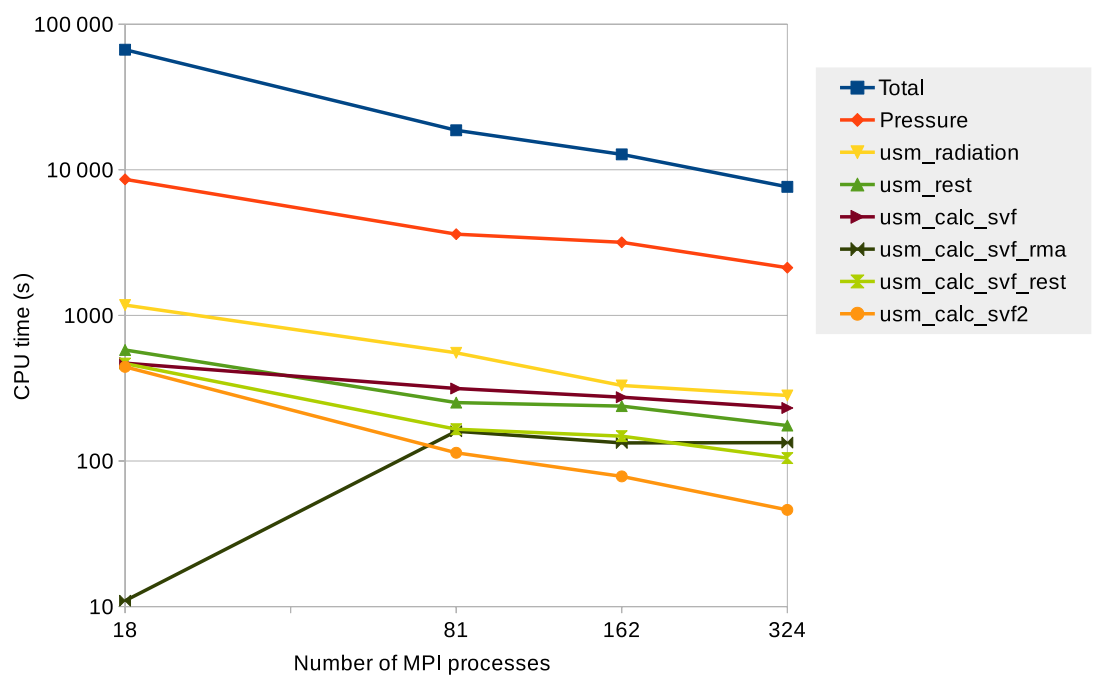

Figure 21. Comparison of the calculation time spent in model PALM-USM and in its chosen parts for various numbers of cores. Model configuration and the meaning of items is the same as in Fig. 20; additionally, usm_calc_svf_rest shows the difference usm_calc_svf$u s m \_c a l c \_s v f \_r m a$ and $u s m \_c a l c \_s v f 2$ depicts $u s m \_c a l c \_s v f$ in the case of the run with option usm_lad_rma set to false.

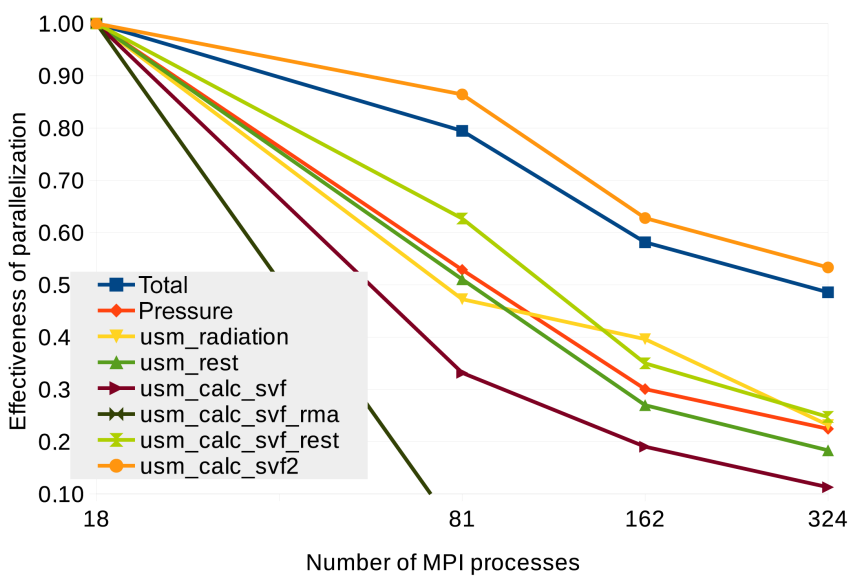

(a)

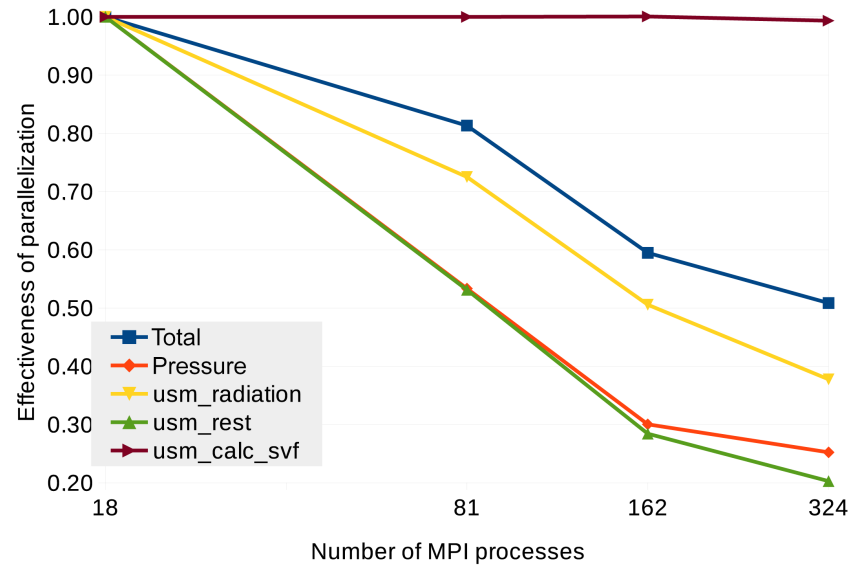

(b)

Figure 22. Effectiveness of the parallelization of the chosen subroutines: (a) simulation with plant canopy, (b) without plant canopy. The meaning of the items is the same as in Fig. 21.

(29\% with plant canopy). However, the direct USM calculation cost presents only about $2 \%$ (4\% with plant canopy) of the total calculation time. The rest of the increase can be attributed to the raised turbulent flow which results in a decreased time step. Figure 20b shows the detailed comparison of USM processes. The initialization time of the USM is dominated by the calculation of SVF and CSF and about half of this calculation is spent with one-sided MPI communication in the case of the run with a plant canopy. The utilization of one-sided MPI routines can be avoided by distributing the global leaf area density (LAD) array into all MPI processes by setting the model configuration parameter usm_lad_rma to false, which reduces the time spent in the USM initialization process and markedly improves the scaling behaviour.
The effectiveness of the parallelization has been tested for a number of MPI processes in the range from 18 to 324 for simulation length $24 \mathrm{~h}$ and the results are shown in Figs. 21 and 22. Figure 21 compares the CPU time needed for calculation of the whole PALM-USM model and its chosen individual parts. Figure 22a and $\mathrm{b}$ show the effectiveness of the parallelization relative to a run with 18 processes for simulation with and without calculation of plant canopy, respectively. The graphs suggest that time-stepping routines usm_radiation and usm_rest scale similarly to calculation of the pressure, which is the most time-consuming individual process of the PALM model. The calculation of SVF during the initialization phase scales excellently in the tested range according to Fig. 22b. Scaling of the calculation of CSF is 
on a par with the whole PALM model for configuration with the LAD array distributed into all processes (Fig. 22a, item usm_calc_svf2), while scaling of the usm_calc_svf is limited by latency of one-sided MPI operations implemented by an Infiniband RMA backend (Fig. 21, usm_calc_svf_rma). (Note that the run with 18 processes fits into one node of the computational cluster and all MPI communication is done through a shared memory backend in our set-up.) On the other hand, it also suggests that the computation of CSF can scale well when the computational domain is extended. However, the testing domain is relatively small and additional tests with larger domains are needed to extract deeper insight into the performance and scaling of PALM-USM. The first tests with the domain extent over $3 \mathrm{~km}$ suggest that the scalability of the present version of RTM is limited by growing memory requirements, particularly by the growth of the number of SVF and CSF. This issue will be solved in the next version of RTM.

\section{Conclusions}

The new model of energy processes in urban environments was developed and integrated into the PALM model as an optional module. The USM utilizes meteorological values calculated by PALM, and it provides sensible heat fluxes as boundary conditions for the atmospheric flow. In this paper, we described the technical details of the USM formulation. Moreover, a first evaluation against data from a measurement campaign in Prague, Czech Republic, was performed, as well as basic sensitivity tests to material parameters. The results are generally in good agreement with observations for our test case. In particular, the evaluation incorporated a detailed comparison of the simulated building wall and street surface temperatures with IR camera measurements. The results showed that the diurnal variation of the surface temperature was very well captured except for the north-facing walls, where the temperatures were overestimated by up to $3{ }^{\circ} \mathrm{C}$. A similar overestimation was also found on some other walls during nighttime hours. These differences can be attributed to inaccurate description of the urban parameters such as heat capacity and conductivity of the wall material as well as to some limitations of the current version of the model and model set-up, e.g. no window model implementation.

Uncertainties due to the sensitivity to the setting of material parameters were estimated in a suite of simulations altering three basic parameters: albedo $( \pm 0.2)$, thermal conductivity, and roughness length (both $\pm 30 \%$ ). The results show that the tested albedo variation generally induces the largest changes in surface temperatures (up to $\pm 5^{\circ} \mathrm{C}$ ). The overall magnitude of changes confirms that the proper setting of material parameters is crucial for the application of the model in real-case simulations.
For tested configurations, the USM shows very moderate computational demand in the context of the other PALM components.

Addressing the current limitations of the USM is a subject of current and future development inside the PALM community. Major changes to the current USM version will involve the implementation of a tile approach to account for windows and green roofs/walls. An energy balance solver for trees will be added in order to explicitly predict the turbulent fluxes of sensible and latent heat from leaves. Also, the wall model will be coupled to an indoor climate and energy demand model, which predicts the indoor temperature, but also the energy demand of the buildings, including anthropogenic waste heat emissions from the buildings due to heating and air conditioning. Furthermore, the scalability of the urban radiative transfer model will be rigorously enhanced to allow for use of larger computational grids. The USM will be coupled to the RRTMG radiation model to improve the radiation input at the top of the urban layer. Finally, the USM will be coupled with the PALM-LSM, which allows one to represent processes related to latent heat (evaporation, transpiration) and urban areas that exhibit larger areas of parks and pervious surfaces compared to the present test case. Many of these actions are work in progress within the framework of the MOSAIK project.

Despite the current limitations, the PALM-USM model provides a new useful tool for climatology studies of urbanized areas, and has been successfully used to simulate urban development scenarios for the city of Prague.

Code availability. The USM code is freely available and it is distributed under GNU General Public License v3 ${ }^{17}$. Its source code is a part of PALM and it has been available for download from the PALM web page ${ }^{18}$ via the SVN server ${ }^{19}$ since PALM revision 2008. The particular version used for computation of the simulations presented in this article is available in branch "resler", revision 2325. This branch version also includes a simple air pollution model.

\section{The Supplement related to this article is available online at https://doi.org/10.5194/gmd-10-3635-2017- supplement.}

Competing interests. The authors declare that they have no conflict of interest.

Acknowledgements. The authors would like to thank three reviewers for the comments that helped to improve the manuscript

\footnotetext{
${ }^{17} \mathrm{http} / / /$ www.gnu.org/copyleft/gpl.html

${ }^{18} \mathrm{https}: / /$ palm.muk.uni-hannover.de

${ }^{19} \mathrm{http}: / /$ subversion.apache.org
} 
considerably. We acknowledge the following projects that supported this research. This work was done within the UrbanAdapt project (EHP-CZ02-OV-1-036-2015) supported by a grant from Iceland, Liechtenstein, and Norway. ${ }^{20}$ This work was also supported by the long-term strategic development financing of the Institute of Computer Science of the Czech Academy of Sciences (RVO:67985807). Some of the simulations were done on supercomputer Salomon, which was supported by the Ministry of Education, Youth and Sports from the Large Infrastructures for Research, Experimental Development and Innovations project IT4Innovations National Supercomputing Center - LM2015070. Coauthors B. Maronga and F. Kanani-Sühring are funded by the German Federal Ministry of Education and Research (BMBF) under grant 01LP1601A (project MOSAIK ${ }^{21}$ ) within the framework of Research for Sustainable Development (FONA ${ }^{22}$ ), which is greatly acknowledged. The authors would like to thank Linton Corbet for language revisions and useful comments. We would also like to thank to the coordinator of UrbanAdapt project Global Change Research Institute (CzechGlobe) for lending the IR camera and František Zemek for his help with the observation campaign. We thank UrbanAdapt project partner the Prague Institute of Planning and Development for providing geographical data and also the ATEM company for its help with the data processing.

Edited by: Jason Williams

Reviewed by: Reinder Ronda and two anonymous referees

\section{References}

Arakawa, A. and Lamb, V. R.: Computational design of the basic dynamical processes of the UCLA general circulation model, in: General Circulation Models of the Atmosphere, edited by: Chang, J., vol. 17 of Methods in Computational Physics: Advances in Research and Applications, 173-265, Elsevier, 1977.

Arnfield, A. J.: Two decades of urban climate research: a review of turbulence, exchanges of energy and water, and the urban heat island, Int. J. Climatol., 23, 1-26, https://doi.org/10.1002/joc.859, 2003.

Balsamo, G., Beljaars, A., Scipal, K., Viterbo, P., van den Hurk, B., Hirschi, M., and Betts, A. K.: A revised hydrology for the ECMWF model: verification from field site to terrestrial water storage and impact in the integrated forecast system, J. Hydrometeorol., 10, 623-643, https://doi.org/10.1175/2008JHM1068.1, 2009.

Berk, A., Conforti, P., Kennett, R., Perkins, T., Hawes, F., and van den Bosch, J.: MODTRAN6: a major upgrade of the MODTRAN radiative transfer code, in: SPIE Defense+ Security, 90880H-90880H, International Society for Optics and Photonics, 2014.

Boland, J., Ridley, B., and Brown, B.: Models of diffuse solar radiation, Renew. Energ., 33, 575-584, 2008.

Clough, S., Shephard, M., Mlawer, E., Delamere, J., Iacono, M., Cady-Pereira, K., Boukabara, S., and Brown, P.: Atmospheric radiative transfer modeling: a summary of

\footnotetext{
${ }^{20}$ http://urbanadapt.cz/en

${ }^{21}$ http://uc2-mosaik.org

22 www.fona.de
}

the AER codes, J. Quant. Spectrosc. Ra., 91, 233-244, https://doi.org/10.1016/j.jqsrt.2004.05.058, 2005.

Dai, Y., Zeng, X., Dickinson, R. E., Baker, I., Bonan, G. B., Bosilovich, M. G., Denning, A. S., Dirmeyer, P. A., Houser, P. R., Niu, G., Oleson, K. W., Schlosser, C. A., and Yang, Z.-L.: The Common Land Model, B. Am. Meteorol. Soc., 84, 1013-1023, https://doi.org/10.1175/BAMS-84-8-1013, 2003.

Deardorff, J. W.: Stratocumulus-capped mixed layers derived from a three-dimensional model, Bound.-Lay. Meteorol., 18, 495-527, https://doi.org/10.1007/BF00119502, 1980.

Ehrhard, J., Khatib, I. A., Winkler, C., Kunz, R., Moussiopoulos, N., and Ernst, G.: The microscale model MIMO: development and assessment, J. Wind Eng. Ind. Aerod., 85, 163-176, 2000.

ENVI-met: ENVI-met 3.1 Manual Contents, available at: http: //www.envi-met.info/documents/onlinehelpv3/helpindex.htm (last access: September 2016), 2009.

FLIR: FLIR SC660 R and D INFRARED CAMERA SYSTEM. Product leaflet, available at: http://www.flir.com/assets/ 6e002ff6acaa46a599ce08197091e01a.pdf (last access: September 2016), 2008.

Grimmond, C. S. B. and Oke, T. R.: Heat storage in urban areas: local-scale observations and evaluation of a simple model, J. Appl. Meteorol., 38, 922-940, https://doi.org/10.1175/15200450(1999)038<0922:HSIUAL>2.0.CO;2, 1999.

Heus, T., van Heerwaarden, C. C., Jonker, H. J. J., Pier Siebesma, A., Axelsen, S., van den Dries, K., Geoffroy, O., Moene, A. F., Pino, D., de Roode, S. R., and Vilà-Guerau de Arellano, J.: Formulation of the Dutch Atmospheric Large-Eddy Simulation (DALES) and overview of its applications, Geosci. Model Dev., 3, 415-444, https://doi.org/10.5194/gmd-3-415-2010, 2010.

Hong, S.-Y., Noh, Y., and Dudhia, J.: A new vertical diffusion package with an explicit treatment of entrainment processes, Mon. Weather Rev., 134, 2318-2341, https://doi.org/10.1175/MWR3199.1, 2006.

Howell, J. R., Menguc, M. P., and Siegel, R.: Thermal Radiation Heat Transfer, CRC Press, 2010.

Järvi, L., Grimmond, C. S. B., and Christen, A.: The Surface Urban Energy and Water Balance Scheme (SUEWS): evaluation in Los Angeles and Vancouver, J. Hydrol., 411, 219-237, https://doi.org/10.1016/j.jhydrol.2011.10.001, 2011.

Juruš, P., Resler, J., Derbek, P., Krč, P., Belda, M., Benešová, N., Vlček, O., Srbová, D., Eben, K., and Hrubeš, P.: High resolution modelling of anthropogenic heat from traffic in urban canopy: a sensitivity study, in: 2016 Smart Cities Symposium Prague (SCSP), 1-6, https://doi.org/10.1109/SCSP.2016.7501031, 2016.

Kanda, M., Inagaki, A., Miyamoto, T., Gryschka, M., and Raasch, S.: A new aerodynamic parametrization for real urban surfaces, Bound.-Lay. Meteorol., 148, 357-377, https://doi.org/10.1007/s10546-013-9818-x, 2013.

Krayenhoff, E. S. and Voogt, J. A.: A microscale threedimensional urban energy balance model for studying surface temperatures, Bound.-Lay. Meteorol., 123, 433-461, https://doi.org/10.1007/s10546-006-9153-6, 2007.

Kusaka, H., Kondo, H., Kikegawa, Y., and Kimura, F.: A simple single-layer urban canopy model for atmospheric models: comparison with multi-layer and slab models, Bound.-Lay. Meteorol., 101, 329-358, https://doi.org/10.1023/A:1019207923078, 2001. 
Letzel, M. O., Krane, M., and Raasch, S.: High resolution urban large-eddy simulation studies from street canyon to neighbourhood scale, Atmos. Environ., 42, 8770-8784, https://doi.org/10.1016/j.atmosenv.2008.08.001, 2008.

Letzel, M. O., Helmke, C., Ng, E., An, X., Lai, A., and Raasch, S.: LES case study on pedestrian level ventilation in two neighbourhoods in Hong Kong, Meteorol. Z., 21, 575-589, https://doi.org/10.1127/0941-2948/2012/0356, 2012.

Lindberg, F., Holmer, B., and Thorsson, S.: SOLWEIG 1.0 - modelling spatial variations of 3D radiant fluxes and mean radiant temperature in complex urban settings, Int. J. Biometeorol., 52, 697-713, https://doi.org/10.1007/s00484-008-0162-7, 2008.

Maronga, B. and Bosveld, F. C.: Key parameters for the life cycle of nocturnal radiation fog: a comprehensive large-eddy simulation study, Q. J. Roy. Meteor. Soc., 143,2463-2480, https://doi.org/10.1002/qj.3100, 2017.

Maronga, B., Gryschka, M., Heinze, R., Hoffmann, F., KananiSühring, F., Keck, M., Ketelsen, K., Letzel, M. O., Sühring, M., and Raasch, S.: The Parallelized Large-Eddy Simulation Model (PALM) version 4.0 for atmospheric and oceanic flows: model formulation, recent developments, and future perspectives, Geosci. Model Dev., 8, 2515-2551, https://doi.org/10.5194/gmd8-2515-2015, 2015.

Martilli, A., Clappier, A., and Rotach, M. W.: An urban surface exchange parameterisation for mesoscale models, Bound.-Lay. Meteorol., 104, 261-304, https://doi.org/10.1023/A:1016099921195, 2002.

Masson, V.: A physically-based scheme for the urban energy budget in atmospheric models, Bound.-Lay. Meteorol., 94, 357-397, https://doi.org/10.1023/A:1002463829265, 2000.

Matzarakis, A., Rutz, F., and Mayer, H.: Modelling radiation fluxes in simple and complex environments: basics of the RayMan model, Int. J. Biometeorol., 54, 131-139, https://doi.org/10.1007/s00484-009-0261-0, 2010

Mirzaei, P. A.: Recent challenges in modeling of urban heat island, Sustain. Cities Soc., 19, 200-206, https://doi.org/10.1016/j.scs.2015.04.001, 2015.

Mirzaei, P. A. and Haghighat, F.: Approaches to study Urban Heat Island - abilities and limitations, Build. Environ., 45, 2192-2201, https://doi.org/10.1016/j.buildenv.2010.04.001, 2010.

Moeng, C.-H. and Wyngaard, J. C.: Spectral analysis of Large-Eddy simulations of the convective boundary layer, J. Atmos. Sci., 45, 3573-3587, https://doi.org/10.1175/15200469(1988)045<3573:SAOLES>2.0.CO;2, 1988.

Moonen, P., Defraeye, T., Dorer, V., Blocken, B., and Carmeliet, J.: Urban physics: effect of the micro-climate on comfort, health and energy demand, Frontiers of Architectural Research, 1, 197-228, https://doi.org/10.1016/j.foar.2012.05.002, 2012.

Musy, M., Malys, L., Morille, B., and Inard, C.: The use of SOLENE-microclimat model to assess adaptation strategies at the district scale, Part 2, Urban Climate, 14, 213-223, https://doi.org/10.1016/j.uclim.2015.07.004, 2015.

Obukhov, A. M.: Turbulence in an atmosphere with a nonuniform temperature, Bound.-Lay. Meteorol., 2, 7-29, https://doi.org/10.1007/BF00718085, 1971.

Oke, T. R.: The energetic basis of the urban heat island, Q. J. Roy. Meteor. Soc., 108, 1-24, https://doi.org/10.1002/qj.49710845502, 1982.
Park, S.-B., and Baik, J.-J.: A Large-Eddy simulation study of thermal effects on turbulence coherent structures in and above a building array, J. Appl. Meteorol. Clim., 52, 1348-1365, https://doi.org/10.1175/JAMC-D-12-0162.1, 2013.

Saiki, E. M., Moeng, C.-H., and Sullivan, P. P.: Large-Eddy simulation of the stably stratified planetary boundary layer, Bound.-Lay. Meteorol., 95, 1-30, https://doi.org/10.1023/A:1002428223156, 2000.

Sailor, D. J. and Lu, L.: A top-down methodology for developing diurnal and seasonal anthropogenic heating profiles for urban areas, Atmos. Environ., 38, 2737-2748, https://doi.org/10.1016/j.atmosenv.2004.01.034, 2004.

Schlünzen, K. H., Hinneburg, D., Knoth, O., Lambrecht, M., Leitl, B., López, S., Lüpkes, C., Panskus, H., Renner, E., Schatzmann, M., Schoenemeyer, T., Trepte, S., and Wolke, R.: Flow and transport in the obstacle layer: first results of the micro-scale model MITRAS, J. Atmos. Chem., 44, 113-130, https://doi.org/10.1023/A:1022420130032, 2003.

Sievers, U.: Das kleinskalige Strömungsmodell MUKLIMO_3 Teil 1: Theoretische Grundlagen, PC-Basisversion und Validierung, Berichte des Deutschen Wetterdienstes 240, Offenbach am Main, Germany, 2012 (in German).

Sievers, U.: Das kleinskalige Strömungsmodell MUKLIMO_3 Teil 2: Thermodynamische Erweiterungen, Berichte des Deutschen Wetterdienstes Entwurf, Offenbach am Main, Germany, 2014 (in German).

Skamarock, W. C., Klemp, J. B., Dudhia, J., Gill, D. O., Barker, D., Duda, M. G., Huang, X.-Y., Wang, W., and Powers, J. G.: A Description of the Advanced Research WRF Version 3, NCAR Tech. Note NCAR/TN-475+STR, 113 pp., NCAR/UCAR, Boulder, 2008.

Tewari, M., Chen, F., Wang, W., Dudhia, J., LeMone, M. A., Mitchell, K., Gayno, G., Ek, M., Wegiel, J., and Cuenca, R. H.: Implementation and verification of the unified NOAH land surface model in the WRF model, 11-15, American Meteorological Society, 20th Conference on Weather Analysis and Forecasting/16th Conference on Numerical Weather Prediction, Seattle, WA, US, presentation, 2004.

United Nations 2014: World Urbanization Prospects: The 2014 Revision, United Nations, Department of Economic and Social Affairs, available at: http://esa.un.org/unpd/wup/, (last access: 12 December 2016), 2014.

Wicker, L. J. and Skamarock, W. C.: Time-splitting methods for elastic models using forward time schemes, Mon. Weather Rev., 130, 2088-2097, https://doi.org/10.1175/15200493(2002)130<2088:TSMFEM>2.0.CO;2, 2002.

Williamson, J. H.: Low-storage Runge-Kutta schemes, J. Comput. Phys., 35, 48-56, https://doi.org/10.1016/0021-9991(80)900339, 1980.

Yaghoobian, N. and Kleissl, J.: An indoor-outdoor building energy simulator to study urban modification effects on building energy use - model description and validation, Energ. Buildings, 54, 407-417, https://doi.org/10.1016/j.enbuild.2012.07.019, 2012.

Yaghoobian, N., Kleissl, J., and Paw U, K. T.: An improved three-dimensional simulation of the diurnally varying street-canyon flow, Bound.-Lay. Meteorol., 153, 251-276, https://doi.org/10.1007/s10546-014-9940-4, 2014. 